\title{
A mathematical model for non-catalytic liquid-solid reversible reactions
}

\author{
F. I. C. C. Pais ${ }^{a *}$ and A. A. T. G. Portugal ${ }^{\mathrm{b}}$ \\ a Delcam International plc, Talbot Way, Small Heath Business Park, Birmingham B10 0HJ, UK \\ ${ }^{b}$ Universidade de Coimbra, Departamento de Engenharia Química, Largo Marquês de Pombal, \\ 3000-Coimbra, Portugal
}

(Received 21 September 1993; revised 2 December 1996)

\begin{abstract}
A sharp interface model has been developed for non-catalytic liquid-solid reversible reactions. It is shown that a sharp reaction interface can occur, in certain circumstances, even if the reaction is reversible. Because the pseudosteady state approximation may not be valid for liquid-solid reactions, this assumption was not made in the model. This led to the need for numerical resolution and the model was solved using orthogonal collocation both in the unreacted core and in the ash layer. Owing to the equilibrium relationship, which holds at the reaction interface, the concentrations of the liquid species are coupled at this location, resulting in a possibly non-linear set of algebraic equations that must be solved in order to evaluate concentrations at the boundaries. An analysis is made of the influence of the parameters that characterize the model. The effect of reversibility is a decrease in the driving force for diffusion. $\odot 1998$ Elsevier Science Ltd. All rights reserved
\end{abstract}

Keywords: Non-catalytic; Reversibility; Diffusion

\section{Notation}

$C=$ concentration $\left(\mathrm{mol} / \mathrm{m}^{3}\right.$ liquid) except $C_{\mathrm{R}}^{\text {in }}(\mathrm{mol} /$ $\mathrm{m}^{3}$ solid)

$D_{\mathrm{e}}=$ effective diffusion coefficient $\left(\mathrm{m}^{2} / \mathrm{s}\right)$

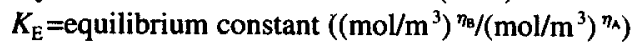

$K_{\mathrm{L}}=$ mass transfer coefficient $(\mathrm{m} / \mathrm{s})$

$n_{11}=$ total number of collocation points in inner zone

$n_{12}=$ total number of collocation points in outer zone

$P M=$ molecular weight

$r=$ radial spatial coordinate $(\mathrm{m})$

$r_{\mathrm{c}}=$ location of the reaction front $(\mathrm{m})$

$R=$ outer radius of the particle $(\mathrm{m})$

$t=$ time (s)

$v_{1}(j, i, k)=$ weight of point $k$ of zone $j$ in the evaluation, using orthogonal collocation, of the first derivative in point $i$ of zone $j$

$v_{2}(j, i, k)=$ weight of point $k$ of zone $j$ in the evaluation, using orthogonal collocation, of the second derivative in point $i$ of zone $j$

$x=$ volumetric conversion of particle

* Author to whom correspondence should be addressed. E-mail: fpg@delcam.com; Fax: +44 (0)1217665511. $y=$ adimensional concentration $\left(C / C^{0}\right)$

Greek letters

$\varepsilon=$ porosity of the particle

$\eta_{1}=$ adimensional spatial coordinate for inner zone

$$
\left(\eta_{1}=\frac{r}{r_{c}}\right)
$$

$\eta_{2}=$ adimensional spatial coordinate for inner zone

$$
\left(\eta_{2}=\frac{r-r_{\mathrm{c}}}{R-r_{\mathrm{c}}}\right)
$$

$\eta=$ stoichiometric coefficient in reaction

$\rho=$ density of solid species $\left(\mathrm{kg} / \mathrm{m}^{3}\right)$

Superscripts

in =referred to initial concentration

$0=$ referred to bulk concentration

Subscripts

$A=$ referred to species $A$

$B=$ referred to species $B$

$c=$ referred to the reaction front

$R=$ referred to species $\mathbf{R}$

$S=$ referred to species $S$

$\mathrm{l}=$ referred to inner zone (unreacted core of particle) 
$2=$ referred to outer zone (ash layer of particle)

\section{Introduction}

Heterogeneous fluid-solid reactions can be divided into catalytic and non-catalytic. Both types are usually influenced to a high degree by heat and mass transfer processes (Doraiswamy and Sharma, 1984). A general heterogeneous reaction, where reactants and products can be either in the solid or fluid phases, can be represented by

$$
\eta_{\mathrm{A}} \mathrm{A}(\mathrm{f})+\eta_{\mathrm{R}} \mathrm{R}(\mathrm{s}) \rightleftharpoons \eta_{\mathrm{B}} \mathrm{B}(\mathrm{f})+\eta_{\mathrm{s}} \mathrm{S}(\mathrm{s})
$$

Examples of non-catalytic fluid-solid reactions are the reduction, roasting and chlorination of ores, decomposition reactions, carbonyl formation, gasification reactions (Doraiswamy and Sharma, 1984) and the causticizing reaction (Angevine, 1983; Blackwell, 1987; Dorris and Allen, 1985, 1986). Two basic types of model have been considered so far: the sharp interface model (SIM) and the homogeneous model (or volume reaction model). The SIM was originally proposed by Yagi and Kunii (1955) as a representation of the conversion of solid particles by reaction with a gas. This model assumes that reaction occurs at a sharp interface between a growing layer of solid product and a shrinking unreacted solid core. The rate controlling step can be either internal diffusion, gas film diffusion or chemical reaction (Levenspiel, 1972). Extensions of this model are the crackling core model (Park and Levenspiel, 1975, 1977) and the grain model (Szekely and Evans, 1970, 1971; Sohn and Szekely, 1972) with or without varying structural properties (Ranade and Harrison, 1979; Georgakis et al., 1979). The homogeneous model holds when the solid is porous and the rate of diffusion of the reactant fluid is high. In this case the fluid will penetrate deeply into the solid and the reaction will take place throughout the particle. Comparison between these two models has been made by several authors (Ishida and Wen, 1968; Doraiswamy and Sharma, 1984). An extensive model review has been published by Ramachandran and Doraiswamy (1982).

For the sharp interface model to be applicable it is not necessary that the unreacted core be totally non-porous. If the reaction is irreversible, it is sufficient that the mass transfer rate be significantly lower than the rate of reaction, and therefore whatever reactant is available via mass transfer can be assumed to react instantly. In this case the progress of the reaction front will depend on local concentration gradients rather than on parameters such as the surface reaction rate constant. No studies have been found in the literature concerning the possibility of a sharp interface model when the reaction is reversible. For the SIM to be valid in these circumstances, it must be ensured that no reaction occurs in the ash layer or in the shrinking core. The main purpose of this study is therefore to determine the applicability of such a model to reversible reactions. An analysis of the phenomena occurring in each zone has already been made by Portugal and Pais (1989) and will be repeated here for the sake of clarity. It is shown that, under certain circumstances, a sharp interface may indeed exist for reversible reactions.

On the other hand, nearly all the analytical model resolutions found in the literature for shrinking core models rely on the pseudo-steady state assumption. Its physical significance is that the interface can be considered stationary at any time, while a steady state diffusion flux is evaluated to find the concentration profile (Doraiswamy and Sharma, 1984). This assumption is valid when the concentration of the reacting fluid phase species in the bulk is much less than the molar density of the solid, that is

$$
\frac{C_{\mathrm{A}}^{0} P M_{\mathrm{R}}}{\rho_{\mathrm{R}}}<10^{-3}
$$

where $C_{\mathrm{A}}^{0}$ is the concentration of the fluid reactant in the bulk, $P M_{\mathrm{R}}$ is the molecular weight of solid species $\mathrm{R}$, and $\rho_{R}$ is the density of solid species $R$. It may not hold for liquid-solid reactions when $C_{\mathrm{A}}^{0}$ has a value comparable to $\frac{\rho_{\mathrm{R}}}{P M_{\mathrm{R}}}$. Because the model developed in this study is to be applied to a liquid-solid reaction, the pseudosteady state assumption was not made so that no limitations exist in the concentrations of the liquid phase species. Analytical solutions found in the literature also assume, for mass transfer-limited models, that the concentration of $\mathrm{A}$ at the reaction interface is nil, which is valid only if the reaction is irreversible.

In this work, a sharp interface model has been developed for reactions of the type described by (1) for cases (such as most liquid-solid reactions) where the pseudo-steady state approximation is not valid. Moreover, reactions have been considered to be reversible rather than irreversible. The model relies on the assumptions that mass transfer (either through ash layer or fluid film) is the limiting step, reversible reaction is instantaneous, and spherical particle is isothermal. If reaction is reversible, the concentrations of the liquid species are coupled at the reaction interface by the equilibrium relationship. They are therefore not known a priori and must be determined during the solution process. Together with the fact that the pseudo-steady state assumption was not made, this led to the need for numerical resolution. Solution is non-trivial since there is a discontinuity in the concentration gradients at the reaction interface and a possibly non-linear system of algebraic equations must be solved in order to determine the concentrations in all the boundaries.

\section{Validity of the sharp interface model for reversible reactions}

In this section, the validity of the SIM model for reversible reactions is analysed. Several authors refer to the causticizing reaction as following a moving-bound- 


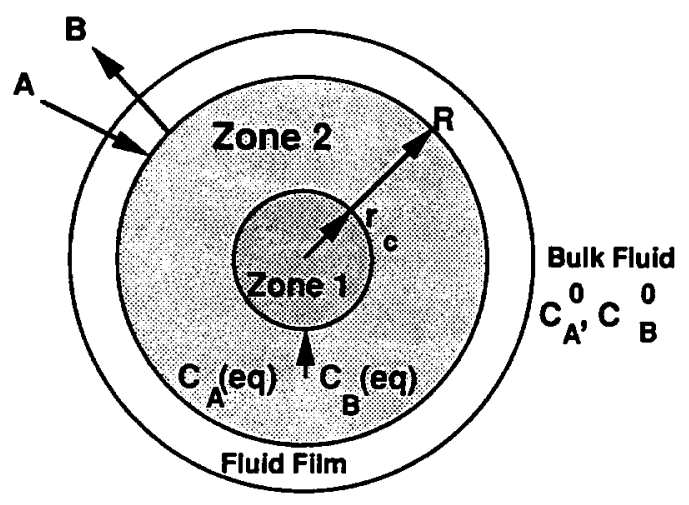

Fig. 1. Schematic representation of the particle undergoing a SIM reaction.

ary pattern (Angevine, 1983; Blackwell, 1987; Dorris and Allen, 1985). However, no model has been found in the literature that could represent this situation for a reversible reaction such as the causticizing reaction. This was therefore one of the first issues approached in this study. Could a sharp interface model exist for a reversible reaction? Based on a study of the fundamental physical and chemical mechanisms involved, it can be concluded that such a situation is possible.

Figure 1 represents graphically the classical SIM pattern, where zone 1 corresponds to the inner shrinking core and Zone 2 to the ash layer:

A very important issue, fundamental to the validity of the model proposed, is, since the reaction is reversible, whether it can be guaranteed that the ash layer does not re-react (reverse reaction) to form solid reactant $\mathrm{R}$ again (in which case a sharp interface model would not be valid). Let us examine in greater detail what happens in this zone.

As the particle is immersed in the bulk liquor and starts to react, a layer of infinitesimal width of $R$ will react with $A$ to produce $S$. At this surface, both $R$ and $S$ are available and both $A$ and $B$ are also available. If the chemical reaction is instantaneous-a commonly used assumption-chemical equilibrium (which determines the ultimate concentrations achievable) is attained instantly, i.e. the concentrations of $\mathrm{A}$ and $\mathrm{B}$ at this layer are such that they satisfy the equilibrium relationship. In a simplified case, let us suppose that the equilibrium relationship depends on the concentrations of the liquid species only. If, for equilibrium concentrations, $K_{\mathrm{E}}=C_{\mathrm{B}}^{\eta_{\mathrm{B}} /}$ $C_{\mathrm{A}}^{\eta_{\mathrm{A}}}$, where $\eta_{\mathrm{A}}$ and $\eta_{\mathrm{B}}$ are the stoichiometric coefficients of $A$ and $B$ in the reversible reaction, respectively, then the concentration of the bulk liquid is such that there is an excess of $\mathrm{A}$ and a deficiency of $\mathrm{B}$, i.e. $C_{\mathrm{B}}^{0} \eta_{\mathrm{B}} / C_{\mathrm{A}}^{0 \eta_{\mathrm{A}}}<K_{\mathrm{E}}$. This condition must be met since the purpose of the reaction is to consume $A$ and produce $B$. If, in the bulk liquid, the relationship of the concentrations were such that $C_{\mathrm{B}}^{0} \eta_{\mathrm{B}} / C_{\mathrm{A}}^{0} \eta_{\mathrm{A}} \geq K_{\mathrm{E}}$, no observable reaction would take place.

As soon as the forward reaction starts, the solid product $S$ is formed and is therefore available for reaction. At the reaction interface, $\mathrm{A}$ is being consumed, producing B. Both A and B were present in the bulk liquid and are present in the whole particle, due to diffusion. Because, in the bulk liquid, there is an excess of $A$ and a deficiency of B with respect to equilibrium, and equilibrium concentrations exist at the reaction front (initially the surface of the particle), A will be transferred from the bulk liquid to the particle, and B will be transferred from the particle to the bulk liquid. As A arrives at the reaction surface, and $B$ leaves it, the concentrations at this point are momentarily disturbed by the diffusion process and will tend to return (instantly) to equilibrium, consuming the excess of $A$ by reaction with the solid reactant $R$, available at the inner core. This causes the movement of the reaction front towards the centre of the particle.

The relationship of the liquid concentrations $\left(C_{\mathrm{B}}^{\eta_{\mathrm{B}}} /\right.$ $C_{\mathrm{A}}^{\eta_{A}}$ ) ranges from an excess of $\mathrm{A}$ in the bulk liquid to equilibrium at the reaction interface. Although $\mathrm{S}, \mathrm{A}$ and $B$ are present in the ash layer, there is an excess of $A$ compared to equilibrium. The reaction is reversible and equilibria are dynamic, so both the forward and reverse reactions take place in this zone simultaneously. However, if an infinitesimal amount of $B$ reacts with $S$, in the ash layer, to form $R$ again, the large amount of $A$ present will immediately react with this amount of $R$. This is due to the fact that excess $\mathrm{A}$, with respect to equilibrium, means in practical terms that the rate of the forward reaction is higher than the rate of the reverse reaction. As a consequence, although $S$ is present, the reverse reaction is not observed, in global terms, because that would draw the concentrations even further from equilibrium, increasing the excess of $A$ with respect to $B$. In other words, the excess of $A$ inhibits the reverse reaction in the ash layer. Therefore, in overall terms (forward-reverse reaction), no observable reaction occurs in this zone since any $\mathrm{R}$ formed is immediately consumed and the forward reaction cannot proceed any further since there is no solid reactant $\mathrm{R}$ available; a layer of $S$ alone will form. Please note that this phenomenon does not depend on the value of the equilibrium constant.

If the reaction is irreversible or the inner core is nonporous, then $\mathrm{A}$ cannot diffuse into the inner core. However, in this study, the reaction is taken to be reversible and the inner core is porous. Since equilibrium is assumed at the reaction interface and therefore the concentration of $\mathrm{A}$ at this location is not zero, $\mathrm{A}$ is also present in the inner core. An equally important issue is whether $\mathbf{R}$ does not react with $A$ in this zone, producing $S$ and therefore invalidating the SIM pattern again. For the set of parameters used in this study, the forward reaction does not take place in this zone, in observable terms, because there is an excess of $B$ and deficiency of $A$, compared with equilibrium, that inhibit the progress of the forward reaction. This is represented quantitatively later, in Section 5 (Fig. 4). While it can be ensured that the concentrations in the ash layer inhibit the reverse reaction from taking place, the same cannot be guaranteed for the inner core with respect to the direct reaction. It does happen for this specific set of parame- 
ters, such that the effective diffusion coefficient of B is twice as large as for A (estimate justified later in the paper) and therefore it is easier for $B$ to diffuse to the centre of the particle. This leads to an excess of $B$, in the inner core, compared with equilibrium. For the values of the effective diffusion coefficients used in this study, the value of the equilibrium constant, i.e. the degree of reversibility, does not seem to influence this phenomenon. This was checked for trial runs of cases with lower values of $K_{\mathrm{E}}$ (namely, all the cases represented in Fig. 8 also resulted in an excess of $B$ in the inner core). A trial run was made for $K_{\mathrm{E}}=500 \mathrm{~mol} / \mathrm{m}^{3}$, for which the concentration of $A$ at the reaction interface is significantly higher than the concentration of $B$ at the same location (reaction is highly reversible), which also resulted in an excess of $\mathrm{B}$ in the inner zone. However, if the effective diffusion coefficient of $A$ in zone 1 is greater than the effective diffusion coefficient of $B$ in the same zone, then A diffuses more easily into the centre of the particle than $B$ and a deficiency of $B$ may exist in this zone, leading to the occurrence of forward reaction in all or part of the shrinking core. This can be observed if the values of the effective diffusion coefficients for $A$ and $B$ are swapped, i.e. value for $A$ twice as large as for $B$ (test runs have been made for this case). For this combination of parameters, the SIM pattern is not valid, although the concentration of $A$ at the reaction interface is much lower than the concentration of $B$, since there is an excess of $A$ in the inner core. Because the concentrations of $A$ and $B$ in the inner core are determined by diffusion alone, their relationship depends on the effective diffu- sion coefficients and on the driving force for diffusion. In this study, the driving force is determined by the concentrations at the reaction interface, which in turn depend on the equilibrium constant and stoichiometric coefficients. Since the model was solved numerically, the conditions for a sharp interface will not be generalized in quantitative terms. However, its existence depends on the value of the effective diffusion coefficients of $\mathrm{A}$ and $\mathrm{B}$ in the inner core, and possibly on the value of the equilibrium constant and stoichiometric coefficients. During simulation, the existence of an excess of $\mathbf{B}$ in the inner core must therefore be verified for the model to be valid.

Summarizing, in the ash layer, the existing solid is S, and $A$ and $B$ are present. However, the reverse reaction is inhibited by the excess of $A$ with respect to equilibrium. In the inner core, for the set of parameters used, the existing solid is $R$, and $A$ and $B$ are also

Table 1. Parameters used for the simulation of the base case

\begin{tabular}{llll}
\hline$C_{\mathrm{A}}^{0}$ & 1150 & $C_{\mathrm{B}}^{0}$ & 600 \\
$C_{\mathrm{R}}^{\text {in }}$ & 25,700 & & \\
$\varepsilon_{1}$ & 0.15 & $\varepsilon_{2}$ & 0.05 \\
$D_{\mathrm{eA} 1}$ & $1 \times 10^{-11}$ & $D_{\mathrm{eB} 1}$ & $2 \times 10^{-11}$ \\
$D_{\mathrm{eA} 2}$ & $3.33 \times 10^{-12}$ & $D_{\mathrm{eB} 2}$ & $6.67 \times 10^{-12}$ \\
$K_{\mathrm{LA}}$ & $5 \times 10^{-4}$ & $K_{\mathrm{LB}}$ & $1 \times 10^{-3}$ \\
$K_{\mathrm{E}}$ & $50 \times 10^{3}$ & $R$ & $5 \times 10^{-5}$ \\
$\eta_{\mathrm{A}}=\eta_{\mathrm{R}}$ & 1 & $\eta_{\mathrm{B}}$ & 2 \\
$P M_{\mathrm{R}}$ & 74.09 & $P M_{\mathrm{S}}$ & 100.09 \\
$\rho_{\mathrm{R}}$ & 2240 & $\rho_{\mathrm{S}}$ & 2710 \\
\hline
\end{tabular}

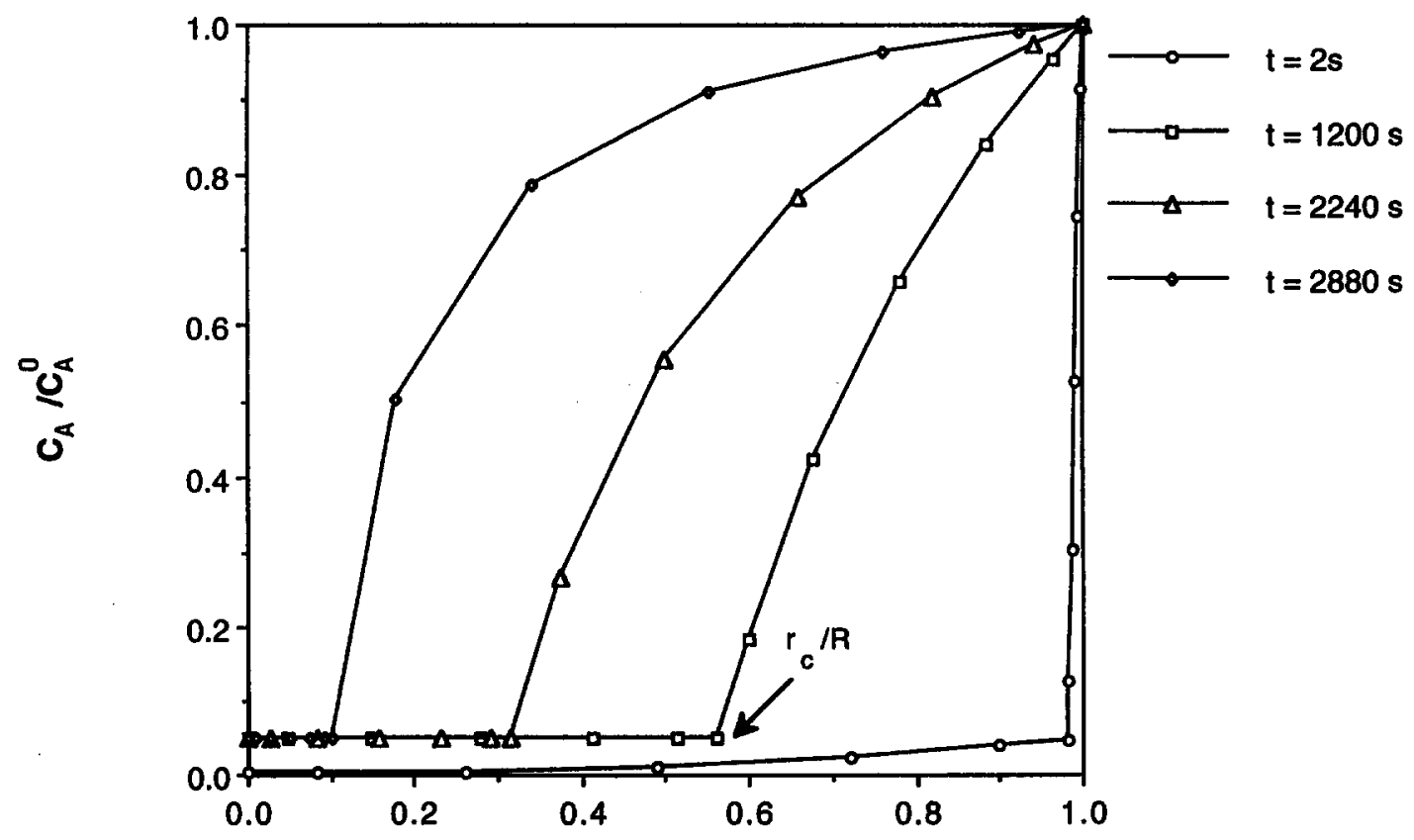

r / R

Fig. 2. Calculated adimensionalized $\mathrm{CO}_{3}^{2-}$ profiles for various values of time $t$. For clarity no interpolated profiles have been calculated and only collocation points are represented and connected by straight lines. 


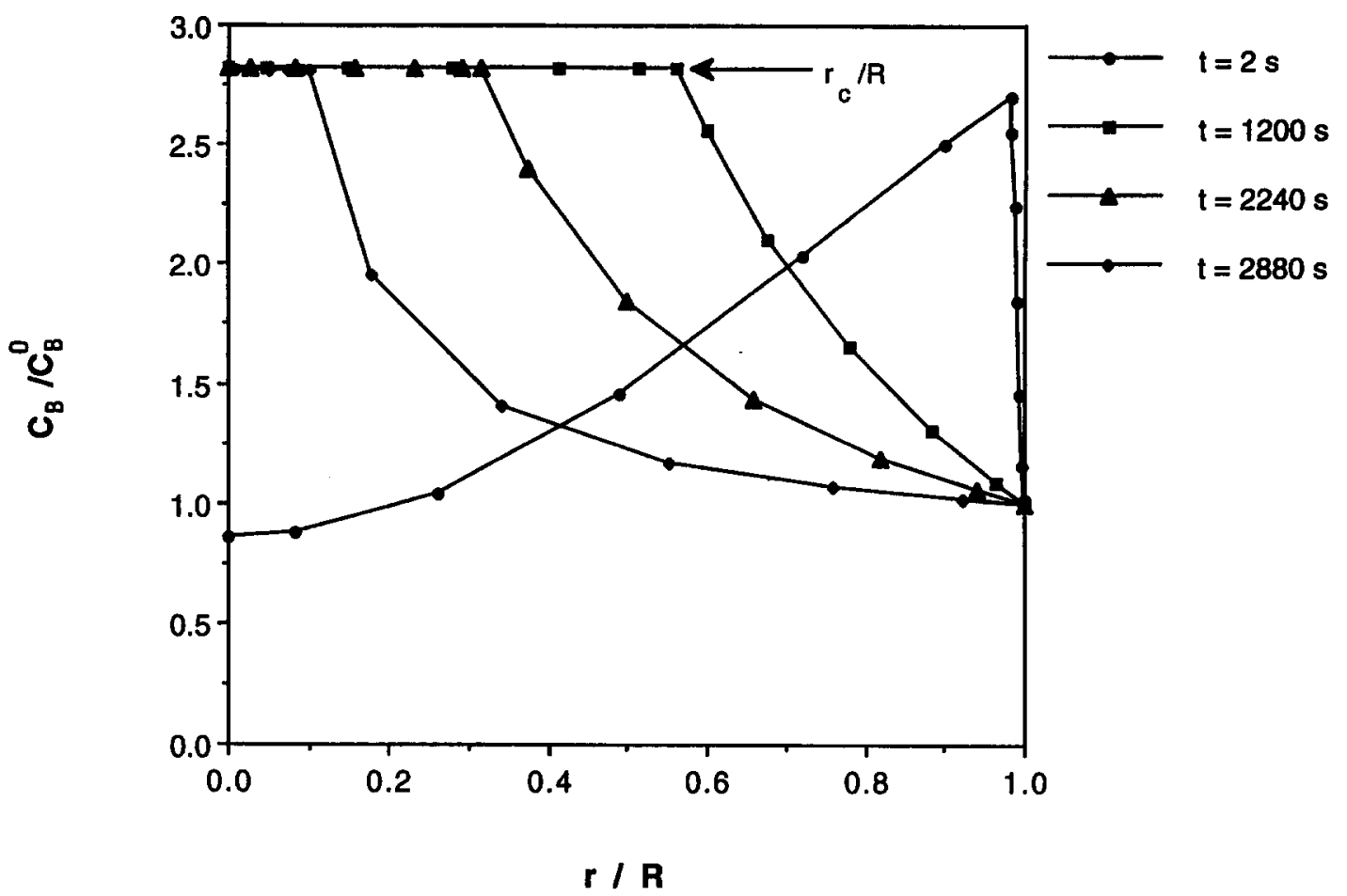

Fig. 3. Calculated adimensionalized $\mathrm{OH}^{-}$profiles for various values of time $t$. For clarity no interpolated profiles have been calculated and only collocation points are represented and connected by straight lines.

present. However, the forward reaction is inhibited by the excess of $B$.

Finally, this discussion was based on the assumption of a mass transfer-limited process. If reaction rate is the limiting step, and since the particle is porous, then both $A$ and $B$ will diffuse into the particle and react before equilibrium is attained at any point in the solid. In this case no sharp interface will form and the heterogeneous reaction is described by the conventional homogeneous or volume reaction model, where both the forward and reverse reactions must be taken into account, as well as the variation of the solids concentrations in space and time.

\section{Formulation of mathematical model}

The distributed model developed for the solid particles is therefore a sharp interface model that assumes the reaction is reversible and mass transfer-limited (either in the fluid film or in the ash layer). If the rate of both forward and reverse reactions is high compared with the rate of mass transfer, then chemical equilibrium exists at the reaction interface. Particles are supposed to be spherical and physical properties of the solid are allowed to be different in the inner shrinking core (zone 1) and ash layer (zone 2), as well as effective diffusion coefficients for liquid species $\mathrm{A}$ and $\mathrm{B}$ in both zones (see Fig. 1).

If the exponents in the equilibrium relationship are taken to be equal to the stoichiometric coefficients in the reversible reaction, then the model is described by the following set of partial differential equations, where $r_{c}$ represents the position of the reaction interface:

$$
\begin{aligned}
\frac{\partial C}{\partial t} & =\frac{D_{\mathrm{e}}}{\varepsilon}\left(\frac{\partial^{2} C}{\partial r^{2}}+\frac{2}{r} \frac{\partial C}{\partial r}\right) 0<r<r_{\mathrm{c}}\left(D_{\mathrm{e}}\right. \\
& \left.=D_{\mathrm{el}}, \varepsilon=\varepsilon_{1}\right)
\end{aligned}
$$

and $r_{\mathrm{c}}<r<R\left(D_{\mathrm{e}}=D_{\mathrm{e} 2}, \varepsilon=\varepsilon_{2}\right), C=C_{\mathrm{A}}, C_{\mathrm{B}}$

$$
\left.\left.\frac{\mathrm{d} r_{\mathrm{c}}}{\mathrm{d} t}=-\frac{1}{C_{\mathrm{R}}^{\mathrm{in}}} \frac{\eta_{\mathrm{R}}}{\eta_{\mathrm{A}}}\left[D_{\mathrm{eA} 2} \frac{\partial C_{\mathrm{A}}}{\partial r}\right)_{r_{\mathrm{c}}^{+}}-D_{\mathrm{eA} 1} \frac{\partial C_{\mathrm{A}}}{\partial r}\right)_{r_{\mathrm{c}}^{-}}\right]
$$

subject to boundary conditions

$$
\begin{gathered}
\frac{\partial C}{\partial r}=0 r=0, C=C_{\mathrm{A}}, C_{\mathrm{B}} \\
K_{\mathrm{L}}\left(C^{0}-C\right)=D_{\mathrm{e} 2} \frac{\partial C}{\partial r} r=R, C=C_{\mathrm{A}}, C_{\mathrm{B}} \\
\left.\left.D_{\mathrm{eA} 2} \frac{\partial C_{\mathrm{A}}}{\partial r}\right)_{r_{\mathrm{c}}^{+}}-D_{\mathrm{eA} 1} \frac{\partial C_{\mathrm{A}}}{\partial r}\right)_{r_{\mathrm{c}}^{-}}=-\frac{\eta_{\mathrm{A}}}{\eta_{\mathrm{B}}}\left[D_{\mathrm{eB} 2} \frac{\partial C_{\mathrm{B}}}{\partial r}\right)_{r_{\mathrm{c}}^{+}} \\
\left.\left.-D_{\mathrm{eB} 1} \frac{\partial C_{\mathrm{B}}}{\partial r}\right)_{r_{\mathrm{r}}^{-}}\right] r=r_{\mathrm{c}}
\end{gathered}
$$




$$
\frac{C_{\mathrm{B}}^{\eta_{\mathrm{B}}}}{C_{\mathrm{A}}^{\eta_{\mathrm{A}}}}=K_{\mathrm{E}} r=r_{\mathrm{c}}
$$

(7) and (8) state that:

a) for a certain amount of reacted A, a corresponding amount of B is produced, according to their stoichiometric relationship;

b) concentrations at the reaction interface obey the equilibrium relationship.

Together with (4), they imply that the rate of advance of the reaction front is such that the concentrations at the interface, momentarily disturbed by the diffusion process, return to their equilibrium values.

As the reaction front approaches the centre of the particle, Zone 1 tends to disappear and only one zone remains. An appropriate way to deal with this problem would be to stop the integration process when the reaction front is very close to the centre of the particle (when $r_{\mathrm{c}}$ tends to zero or, for numerical purposes, when $r_{c}$ is lower than a certain tolerance), which corresponds to a fully reacted particle. In this study a different approach was taken since the model for the solid particles was to be used as a component of a larger model for the determination of the steady-state of twophase continuous stirred tank reactors (see Pais and Portugal, 1994, 1996). In the model for the CSTR it is necessary to know the state (i.e. the internal concentration profiles) of the particles for the entire age range (i.e., from 0 to $+\infty$ ), which implies that the integration process should continue after the particle was thoroughly reacted. In order to avoid switching from two distinct zones to a single one, eqs. (9-10) were used as the boundary conditions at the reaction interface, replacing eqs. (7-8). In practice eqs. (9-10) state that there is continuity of fluxes across the interface, so both zones behave as one and diffusion alone takes place. If it is not necessary to know the behaviour of the particle after it has fully reacted, then the use of an ODE solver which stops at this point would be simpler and is recommended.

$$
\begin{aligned}
& \left.\left.D_{\mathrm{eA} 2} \frac{\partial C_{\mathrm{A}}}{\partial r}\right)_{r_{\mathrm{c}}^{+}}=D_{\mathrm{eA} 1} \frac{\partial C_{\mathrm{A}}}{\partial r}\right)_{r_{\mathrm{c}}^{-}} r=r_{\mathrm{c}} \\
& \left.\left.D_{\mathrm{eB} 2} \frac{\partial C_{\mathrm{B}}}{\partial r}\right)_{r_{\mathrm{c}}^{+}}=D_{\mathrm{eB} 1} \frac{\partial C_{\mathrm{B}}}{\partial r}\right)_{r_{\mathrm{c}}^{-}} r=r_{\mathrm{c}} .
\end{aligned}
$$

As a consequence, the reaction interface ceases to advance.

Initial conditions are:

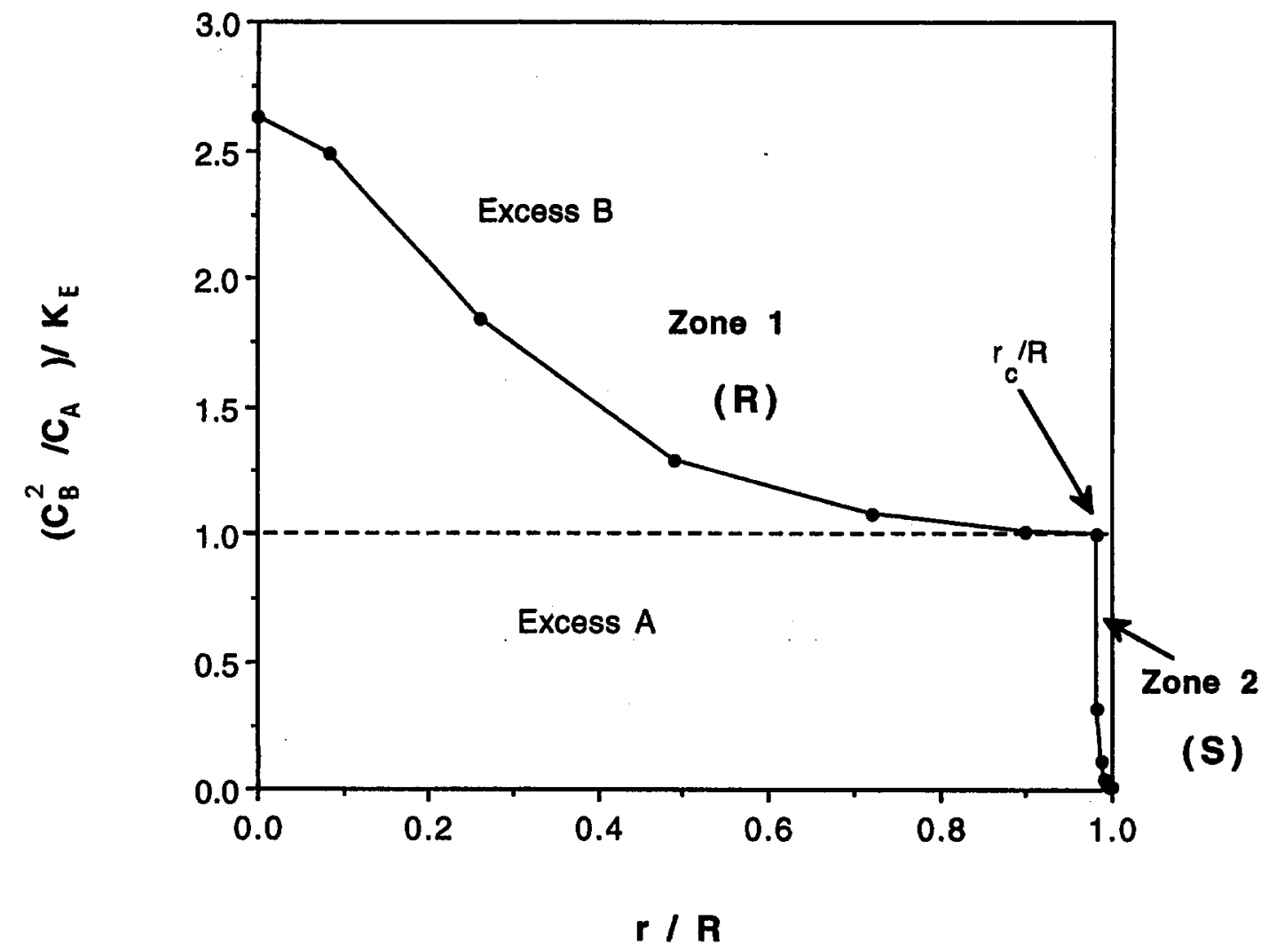

Fig. 4. Variation of the ratio $\frac{C_{\mathrm{B}}^{2} / C_{\mathrm{A}}}{K_{\mathrm{E}}}$ for $t=2 \mathrm{~s}$ (see Fig. 2 and Fig. 3). 
Model for non catalytic liquid-solid reversible reactions

$$
\begin{gathered}
C=C^{\text {in }} t=0, C=C_{\mathrm{A}}, C_{\mathrm{B}} \\
r_{\mathrm{c}}=r_{\mathrm{c}}^{\text {in }} t=0
\end{gathered}
$$

\subsection{Adimensionalization of dependent and independent} variables

The model was solved using orthogonal collocation (Villadsen and Michelsen, 1976) in both the unreacted core and the ash layer, using (7) and (8) or (9) and (10) to couple the two zones. The position $r$ along the radius of the particle was used as the spatial independent variables.

In order to immobilize the moving boundary, a change of variables similar to the one used by Stamatakis and Tien (1991) can be made. If $y_{\mathrm{A}}=\frac{C_{\mathrm{A}}}{C_{\mathrm{A}}^{0}}, y_{\mathrm{B}}=\frac{C_{\mathrm{B}}}{C_{\mathrm{B}}^{0}}, \eta_{\mathrm{1}}=\frac{r}{r_{\mathrm{c}}}$, $\eta_{2}=\frac{r-r_{\mathrm{c}}}{R-r_{\mathrm{c}}}$ and $\eta_{\mathrm{c}}=\frac{r_{\mathrm{c}}}{R}$, then the equations that describe the model are

$$
\begin{gathered}
\frac{\partial y}{\partial t}-\frac{\partial y}{\partial \eta_{\mathrm{l}}} \frac{\eta_{\mathrm{l}}}{\eta_{\mathrm{c}}} \frac{\mathrm{d} \eta_{\mathrm{c}}}{\mathrm{d} t}=\frac{D_{\mathrm{el}}}{\varepsilon_{1} \eta_{\mathrm{c}}^{2} R^{2}}\left(\frac{\partial^{2} y}{\partial \eta_{1}^{2}}+\frac{2}{\eta_{1}} \frac{\partial y}{\partial \eta_{1}}\right) \\
0<\eta_{1}<1, y=y_{\mathrm{A}}, y_{\mathrm{B}}
\end{gathered}
$$

$$
\begin{aligned}
\frac{\partial y}{\partial t}- & \frac{\partial y}{\partial \eta_{2}} \frac{1-\left(\eta_{2}\left(1-\eta_{\mathrm{c}}\right)+\eta_{\mathrm{c}}\right)}{\left(1-\eta_{\mathrm{c}}\right)^{2}} \frac{\mathrm{d} \eta_{\mathrm{c}}}{\mathrm{d} t} \\
& =\frac{D_{\mathrm{e} 2}}{\varepsilon_{2}} \frac{1}{R^{2}\left(1-\eta_{\mathrm{c}}\right)}\left[\frac{1}{1-\eta_{\mathrm{c}}} \frac{\partial^{2} y}{\partial \eta_{2}^{2}}\right. \\
& \left.+\frac{2}{\eta_{2}\left(1-\eta_{\mathrm{c}}\right)+\eta_{\mathrm{c}}} \frac{\partial y}{\partial \eta_{2}}\right] \\
0 & <\eta_{2}<1, y=y_{\mathrm{A}}, y_{\mathrm{B}}
\end{aligned}
$$

$$
\frac{\mathrm{d} \eta_{\mathrm{c}}}{\mathrm{d} t}=-\frac{C_{\mathrm{A}}^{0}}{R^{2} C_{\mathrm{R}}^{\mathrm{in}}} \frac{\eta_{\mathrm{R}}}{\eta_{\mathrm{A}}}\left[\frac{D_{\mathrm{eA} 2}}{1-\eta_{\mathrm{c}}} \frac{\partial y_{\mathrm{A}}}{\partial \eta_{2}}\right)_{\eta_{2}=0}
$$$$
\left.\left.-\frac{D_{\text {eAI }}}{\eta_{\mathrm{c}}} \frac{\partial y_{\mathrm{A}}}{\partial \eta_{1}}\right)_{\eta_{1}=1}\right]
$$

$$
\frac{1}{\eta_{\mathrm{c}} R} \frac{\partial y}{\partial \eta_{1}}=0 \quad \eta_{1}=0, y=y_{\mathrm{A}}, y_{\mathrm{B}}
$$

$$
K_{\mathrm{L}}(1-y)=\frac{D_{\mathrm{e} 2}}{R\left(1-\eta_{\mathrm{c}}\right)} \frac{\partial y}{\partial \eta_{2}} \eta_{2}=1, y=y_{\mathrm{A}}, y_{\mathrm{B}}
$$

$$
\left.\left.\frac{D_{\mathrm{eA} 2}}{1-\eta_{\mathrm{c}}} \frac{\partial y_{\mathrm{A}}}{\partial \eta_{2}}\right)_{\eta_{\mathrm{z}}=0}-\frac{D_{\mathrm{eA} 1}}{\eta_{\mathrm{c}}} \frac{\partial y_{\mathrm{A}}}{\partial \eta_{1}}\right)_{\eta_{1}=1}
$$

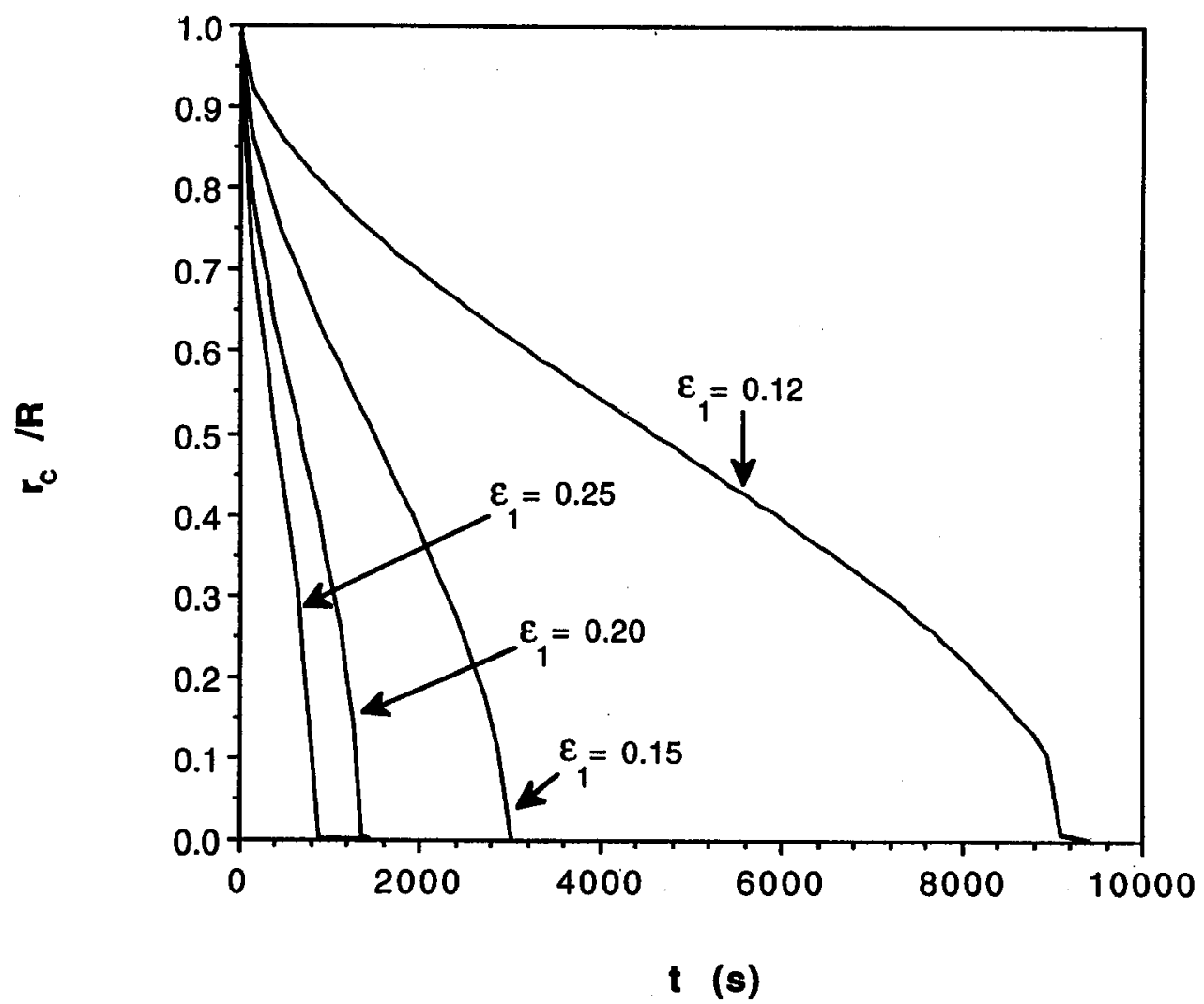

Fig. 5. Influence of porosity and effective diffusion coefficients on the advance of the reaction front with time. 


$$
\begin{gathered}
=-\frac{\eta_{\mathrm{A}}}{\eta_{\mathrm{B}}} \frac{C_{\mathrm{B}}^{0}}{C_{\mathrm{A}}^{0}}\left[\frac{D_{\mathrm{eB} 2}}{1-\eta_{\mathrm{c}}} \frac{\partial y_{\mathrm{B}}}{\partial \eta_{2}}\right)_{\eta_{2}=0} \\
\left.\left.-\frac{D_{\mathrm{eB} 1}}{\eta_{\mathrm{c}}} \frac{\partial y_{\mathrm{B}}}{\partial \eta_{1}}\right)_{\eta_{1}=1}\right] \eta_{1}=1, \eta_{2}=0 \\
\frac{y_{\mathrm{B}}^{\eta_{\mathrm{B}}}}{y_{\mathrm{A}}^{\eta_{\mathrm{A}}}}=K_{\mathrm{E}} \frac{C_{\mathrm{A}}^{0 n^{n A}}}{C_{\mathrm{B}}^{0 \text { nd }}} \eta_{1}=1, \eta_{2}=0 .
\end{gathered}
$$

Eqns $(9-10)$ become eqns. (20-21):

$$
\begin{aligned}
& \left.\left.\frac{D_{\mathrm{eA} 2}}{1-\eta_{\mathrm{c}}} \frac{\partial y_{\mathrm{A}}}{\partial \eta_{2}}\right)_{\eta_{3}=0}=\frac{D_{\mathrm{eA} 1}}{\eta_{\mathrm{c}}} \frac{\partial y_{\mathrm{A}}}{\partial \eta_{1}}\right)_{\eta_{1}=1} \eta_{1}=1, \eta_{2}=0 \\
& \left.\left.\frac{D_{\mathrm{eB} 2}}{1-\eta_{\mathrm{c}}} \frac{\partial y_{\mathrm{B}}}{\partial \eta_{2}}\right)_{\eta_{2}=0}=\frac{D_{\mathrm{eB} 1}}{\eta_{\mathrm{c}}} \frac{\partial y_{\mathrm{B}}}{\partial \eta_{1}}\right)_{\eta_{1}=1} \eta_{1}=1, \eta_{2}=0 .
\end{aligned}
$$

\section{Numerical solution}

As mentioned before, this model was solved by orthogonal collocation in both zones using $r$ as the spatial independent variable (see Appendix A). The resulting system of ODEs was then solved by the BDF method using subroutine LSODI (Hindmarsh, 1980). In the general case where the equilibrium relationship is non-linear the system of unknowns corresponding to the variables at the boundaries has to be solved by means of a formula (for degrees up to 3 ) or by a numerical method for non-linear equations (see Appendix B).

The base case corresponds to the causticizing reaction, which is a liquid-solid reversible reaction that has been repeatedly described as following a movingboundary model (Angevine, 1983; Blackwell, 1987; Dorris and Allen, 1985, 1986):

$$
\mathrm{CO}_{3}^{2-}(\mathrm{aq})+\mathrm{Ca}(\mathrm{OH})_{2}(\mathrm{~s}) \rightleftharpoons 2 \mathrm{OH}^{-}(\mathrm{aq})+\mathrm{CaCO}_{3}(\mathrm{~s})(22)
$$

Most of the parameters used correspond to the ones used in the causticizing reaction in paper pulp mills. The set of data used for the simulation of the base case is presented in Table 1.

Values for $P M_{\mathrm{R}}, P M_{\mathrm{S}}, \rho_{\mathrm{R}}$ and $\rho_{\mathrm{S}}$ were taken from Weast (1983). It was assumed, for the base case, that the order of magnitude of the effective diffusion coefficients was $10^{-11}$, which has been verified for a number of alcohols in water (Blasiński and Amanowitz, 1979). The parameter $D_{\mathrm{eB}}$ was always assumed to be twice greater than $D_{\mathrm{eA}}$, which is approximately verified for the diffusion coefficients of $\mathrm{NaOH}$ and $\mathrm{Na}_{2} \mathrm{CO}_{3}$ in aqueous solutions (Leaist and Noulty, 1985; Noulty and Leaist, 1984). Supposing that a simple relationship such as $D_{\mathrm{e}}=D \frac{\varepsilon}{\tau}$, where $D$ is the diffusion coefficient and $\tau$ is the tortuosity, holds, then values of $D_{\epsilon}$ for several porosities can be evaluated, if $\tau$ is constant:

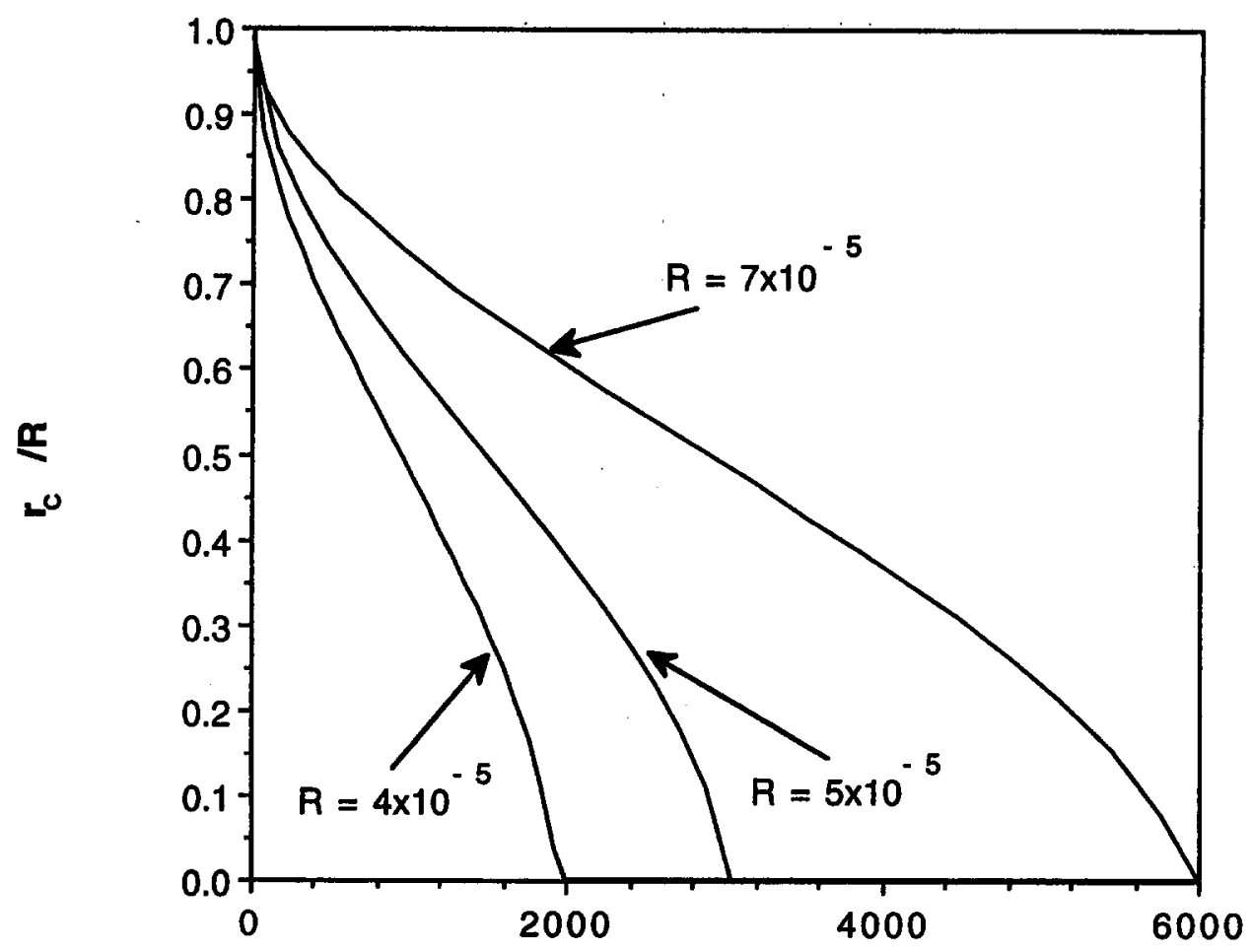

t (s)

Fig. 6. Influence of the outer radius of the particle $R$ on the advance of the reaction front with time. 


$$
\frac{D_{\mathrm{e}}^{\prime}}{D_{\mathrm{e}}}=\frac{\varepsilon^{\prime}}{\varepsilon} \text {. }
$$

This relationship was used to estimate the values of the effective diffusion coefficients for several porosities (always taking the base case for $D_{\mathrm{e}}$ and $\varepsilon$ ).

If a decrease in the porosity of the ash layer is attributed to the increase in the molar volume of the solid alone (Dorris and Allen, 1985), then the following relationship can be established between the porosity in the shrinking core and the ash layer:

$$
\varepsilon_{2}=(1-\alpha)+\alpha \varepsilon_{1}
$$

where

$$
\alpha=\frac{\rho_{\mathrm{R}}}{\rho_{\mathrm{S}}} \frac{P M_{\mathrm{S}}}{P M_{\mathrm{R}}} .
$$

For the values corresponding to $\mathrm{Ca}(\mathrm{OH})_{2}$ and $\mathrm{CaCO}_{3}$, we then have $\varepsilon_{2}=-0.117+1.117 \varepsilon_{1}$.

It is obvious that a lower limit exists for $\varepsilon_{1}$ so that $\varepsilon_{2}$ is always greater or equal to zero. In this case the limit is $\varepsilon_{1}=0.105$. The physical meaning of this limitation is that although pore closure may occur and reduce the ash layer porosity, theoretically to zero (total pore closure), the initial void volume must be enough to accommodate the increase in volume, otherwise structural changes such as cracking and fissuring would have to be considered. Although they can also be dealt with, they are outside the scope of this work.

Concentration of the bulk liquid corresponds to green liquor concentration used in the paper pulp industry (Rydin, 1978).

A large number of papers published, usually in connection with the paper pulp industry, directly addresses the issue of the reversibility of the causticizing reaction as the main factor which limits the maximum conversion of the reaction. The value used for the equilibrium constant is an average value taken from experimental studies that aim to determine the (apparent) equilibrium constant over a range of concentrations (Lindberg and Ulmgren, 1983; Dorris, 1990). A mass balance may be made, with the parameters used in the paper, to evaluate the extension of the reaction for this value of the equilibrium constant. The concentration of $A$ in the bulk liquid, $C_{\mathrm{A}}^{0}$, is $1150 \mathrm{~mol} / \mathrm{m}^{3}=1.15 \mathrm{~mol} / \mathrm{l}$, whereas $C_{\mathrm{B}}^{0}=600 \mathrm{~mol} / \mathrm{m}^{3}=0.6 \mathrm{~mol} / 1$. If the bulk liquid is allowed to reach equilibrium, taking $K_{\mathrm{E}}$ to be $5 \times 10^{4} \mathrm{~mol} / \mathrm{m}^{3}=50 \mathrm{~mol} / 1$, the amount of $A$ that reacts is $1.012 \mathrm{~mol} / \mathrm{l}$. Although equilibrium is displaced to the right, towards the products (which is why this reaction is used to produce an appreciable amount of $\mathrm{OH}^{-}$ions), the fraction of unreacted $A$ remaining is $12 \%$, far too high to be considered negligible. This value for $K_{\mathrm{E}}$ was taken, together with the rest of the parameters, because it corresponds to a real chemical reaction and is therefore

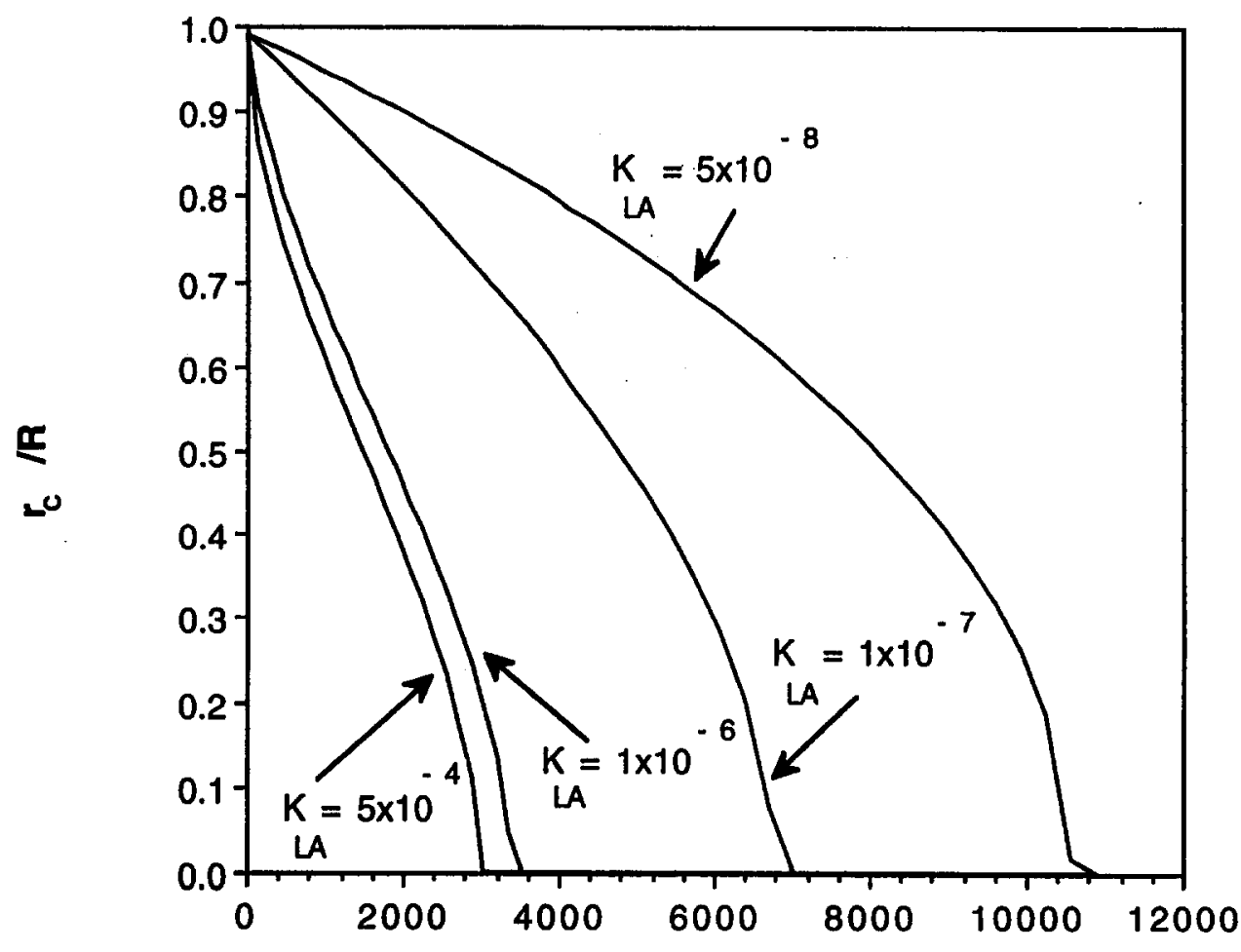

t (s)

Fig. 7. Influence of mass transfer coefficients on the advance of the reaction front with time. 
more meaningful than an arbitrary value. However, as discussed in Section 2, the applicability of this model does not depend on the value of $K_{\mathrm{E}}$ and it can be used for other values of the equilibrium constant.

Molar concentration of the solid reactant was evaluated from its density, molecular weight and arbitrated porosity. Values for the mass transfer coefficients were chosen arbitrarily. The outer radius of the particle was also arbitrated.

\section{Results and discussion}

Variation of the parameters that define the model has been performed in order to study their influence. The particle is physically characterized by $\varepsilon_{1}$ and $\varepsilon_{2}, C_{\mathrm{R}}^{\text {in }}$ and $R$. The parameters that define mass transfer properties are $D_{\mathrm{eA} 1}, D_{\mathrm{eA} 2}, D_{\mathrm{eB} 1}$ and $D_{\mathrm{eB} 2}$, as well as $K_{\mathrm{LA}}$ and $K_{\mathrm{LB}}$. Reactional parameters are the equilibrium constant, $K_{\mathrm{E}}$, and the stoichiometric coefficients $\eta_{\mathrm{A}}$ and $\eta_{\mathrm{B}}$.

Profiles obtained for the base case correspond to Figs 2 and 3.

As far as $\mathrm{A}\left(\mathrm{CO}_{3}^{2-}\right)$ is concerned, it must be noted that the gradient of the concentration profile at $r_{\mathrm{c}}$ increases as the reaction front approaches the centre of the particle. There is at first an increase in the local concentration of $\mathrm{B}\left(\mathrm{OH}^{-}\right)$in the reaction front. The inner zone is then quickly flooded with product $B$ and its concentration becomes equal to the equilibrium concentration.
Figure 4 shows the ratio $\frac{C_{\mathrm{B}}^{2} / C_{\mathrm{A}}}{K_{\mathrm{E}}}$ for the values of the concentrations of A and B presented in Figs 2 and 3, for $t=2 \mathrm{~s}$.

Note that an excess of $A$ exists in all of the ash layer, and an excess of $B$ exists in all of the inner core. This is due to the fact that $B$ diffuses more easily towards the centre of the particle than $A$, due to its higher effective diffusion coefficient. What determines the occurrence of an observable reversible reaction (forward-reverse) is not merely the presence of the necessary reactants and products, but also the relationship of the concentrations involved. Excess A means that the forward reaction is faster than the reverse reaction, and therefore if such an excess is imposed, no solid reactant $R$ is left although both forward and reverse reactions take place.

The influence of porosity of the original particle and, accordingly, porosity of the ash layer has also been studied (see Fig. 5). Diffusion coefficients have been varied proportionally around their base values.

As could be expected, smaller porosities and effective diffusion coefficients lead simply to a slower advance of the reaction front. Although the pseudo-steady state assumption was not made in this case and effective diffusion coefficients are different on both sides of the interface, the shape of the curve matches closely the one presented in the literature (Levenspiel, 1972), obtained analytically, using the pseudo-steady state assumption,

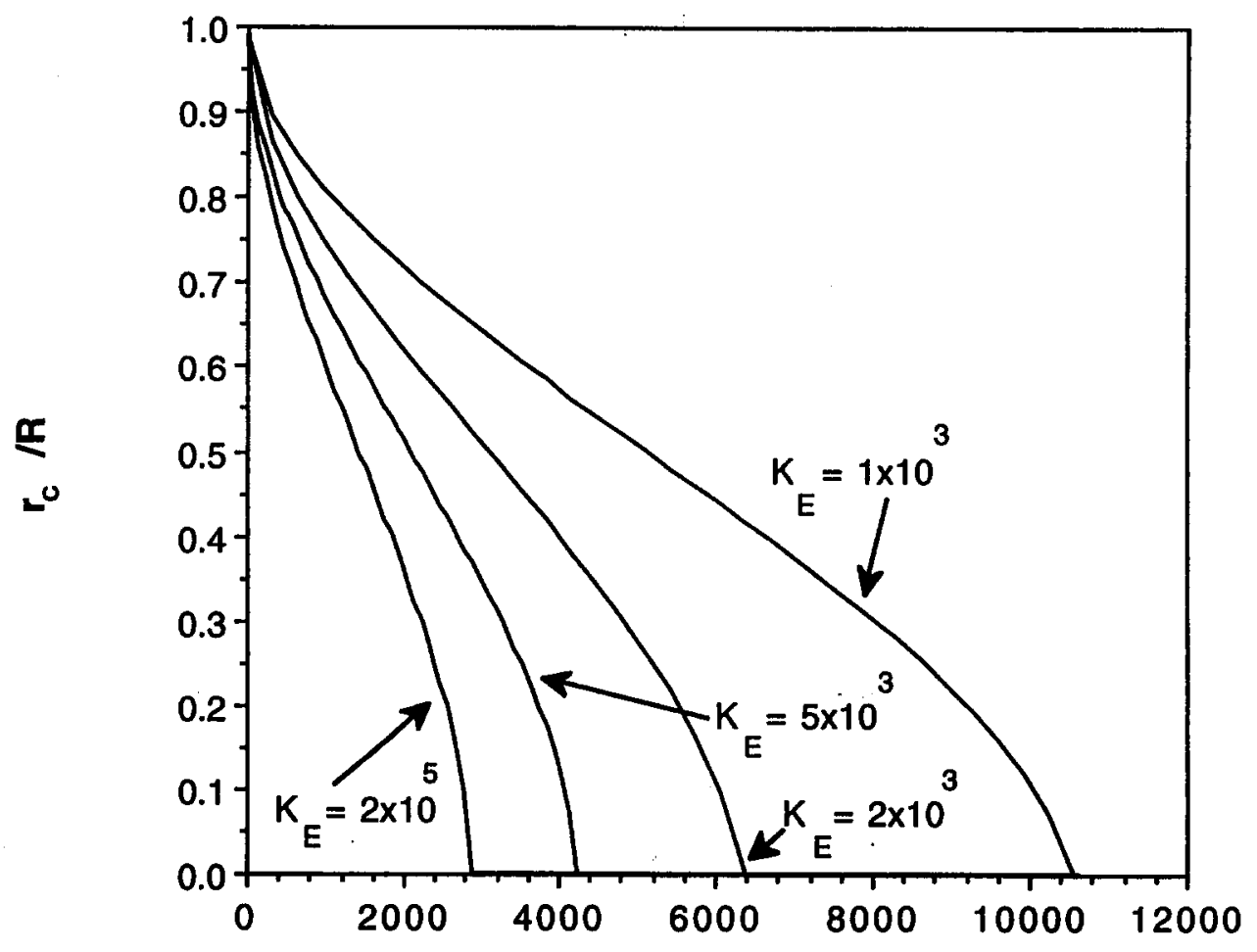

t (s)

Fig. 8. Influence of the equilibrium constant on the advance of the reaction front with time. 
and assuming irreversible reaction and ash-layer diffusion control

$$
t / \tau=1-3\left(\frac{r_{\mathrm{c}}}{R}\right)^{2}+2\left(\frac{r_{\mathrm{c}}}{R}\right)^{3}
$$

where $\tau$ is the time for the particle to react completely. For this specific set of parameters, the pseudo-steady state assumption may be valid (although that might not occur for more concentrated solutions). It is logical that the shape be similar since both models consider two purely diffusional zones, separated by a moving boundary. However, although the shape of the curve is similar, the values of $\tau$ obtained are different (higher) from the ones obtained by Levenspiel. For ash-diffusion control, the analytical solution yields

$$
\tau=\frac{C_{\mathrm{R}}^{\mathrm{in}} R^{2}}{6 \frac{\eta_{R}}{\eta_{\mathrm{A}}} D_{\mathrm{eA} 2} C_{\mathrm{A}}^{0}} .
$$

For the base case $\left(\varepsilon_{1}=0.15\right)$ this corresponds to a value of $\tau$ of $2796 \mathrm{~s}$, whereas the results obtained by our model give, for the same case, a value of $\tau$ of about $3020 \mathrm{~s}$ (we are using the term approximately since the equations are being solved numerically and therefore the time that is considered for the particle to react completely depends on the numerical tolerance used). This difference is noticeable already, considering that the equilibrium is displaced to the right to a considerable extent. Furthermore, as will be shown in Fig. 8, this difference increases with lower values of the equilibrium constant.

Different sizes of the particle-which correspond to different values of the characteristic dimension $R$ result, as expected, simply in a slower advance of the reaction front for higher values of $R$ (see Fig. 6).

Several values of $K_{\mathrm{L}}$ have been tested (see Fig. 7).

Once again it can be seen that the shape of the $r_{\mathrm{c}}(t) / R$ versus $t / \tau$ curve matches the analytical solution previously mentioned as the value of $K_{\mathrm{L}}$ decreases. The change in the shape of the curve, as $K_{\mathrm{L}}$ decreases and the process becomes fluid film diffusion-controlled, is also similar to the one presented by Levenspiel (1972).

To study the influence of the reversibility of the reaction, which is the main purpose of this work, several values of $K_{\mathrm{E}}$ have been tested (see Fig. 8).

It can be seen that smaller values of $K_{\mathrm{E}}$ lead to a slower advance of the reaction front without any significant change in the shape of the curve. This is understandable as lower values of $\mathrm{K}_{\mathrm{E}}$ correspond to a higher concentration of $\mathrm{A}$, in this case $\mathrm{CO}_{3}^{2-}$, at the reaction front and therefore to smaller driving forces for diffusion.

By slower advance of the reaction front we actually mean greater values of $\tau$. Two important observations

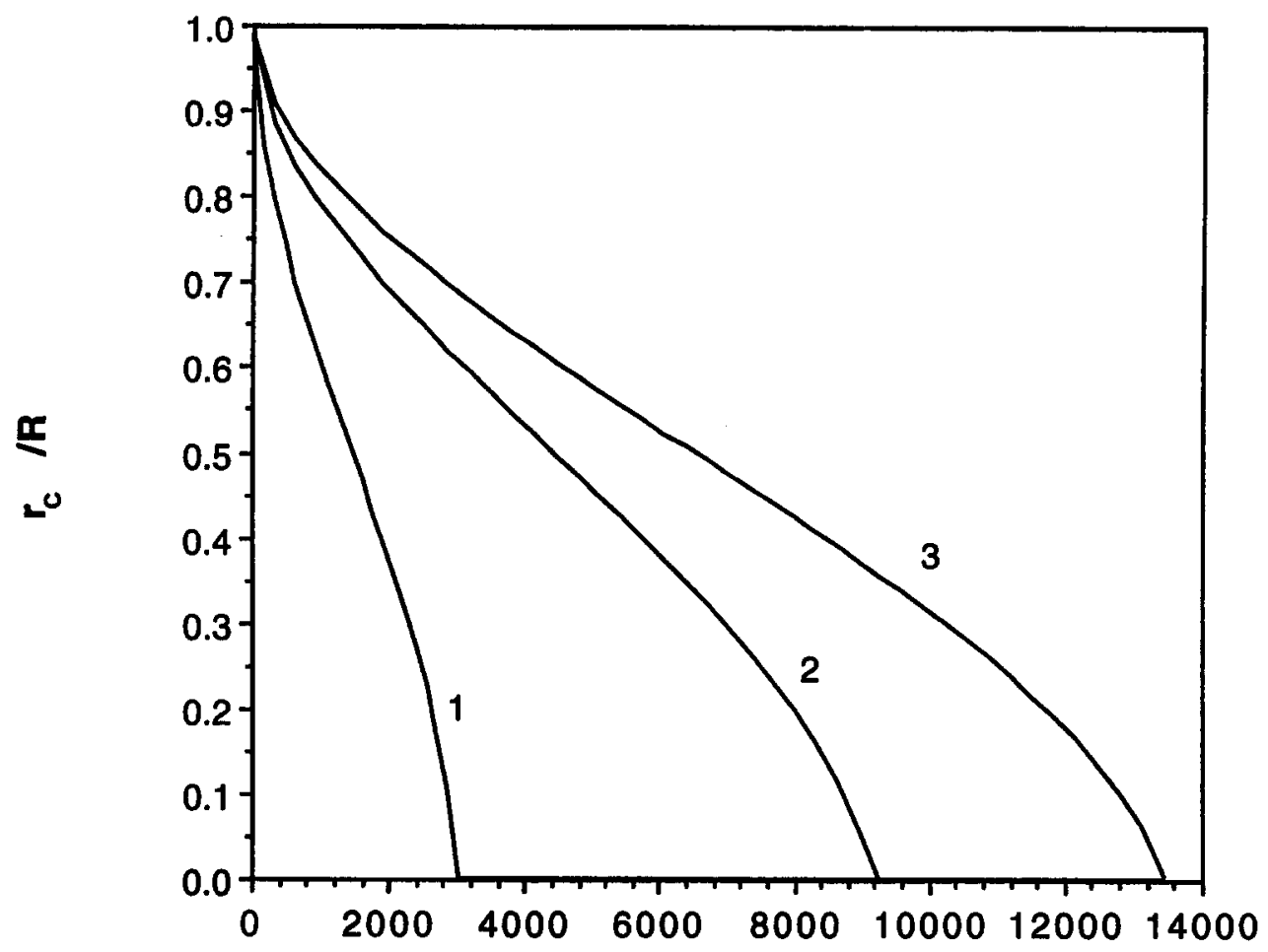

t (s)

Fig. 9. Influence of different equilibrium constants and stoichiometric coefficients on the advance of the reaction front with time. Curve 1: $\eta_{\mathrm{A}}=1, \eta_{\mathrm{B}}=2, K_{\mathrm{E}}=50 \times 10^{3} ;$ Curve 2: $\eta_{\mathrm{A}}=2, \eta_{\mathrm{B}}=2, K_{\mathrm{E}}=5 ;$ Curve 3: $\eta_{\mathrm{A}}=3, \eta_{\mathrm{B}}=2, K_{\mathrm{E}}=1 \times 10^{-2}$. 
can be made from Fig. 8. The first one is that as reaction tends to irreversibility, i.e. as $K_{\mathrm{E}} \rightarrow \infty$ (see the curve obtained for $K_{\mathrm{E}}=2 \times 10^{5} \mathrm{~mol} / \mathrm{m}^{3}$ ), the value of $\tau$ tends to the one obtained by the analytical resolution presented by Levenspiel. The second one is that, as the degree of reversibility of the reaction increases, the value of $\tau$ totally diverges from the value presented by Levenspiel, increasing as the value of $K_{\mathrm{E}}$ decreases. For $K_{\mathrm{E}}=10^{3}$, the time taken for the particle to react completely is over $10,400 \mathrm{~s}$. This variation is as expected, since for lower values of $K_{\mathrm{E}}$ the concentrations at the reaction front are closer to the bulk liquid ones and the driving force for diffusion is lower (totally unaccounted for in previous models).

The same kind of behaviour is observed for different values of the stoichiometric coefficients and equilibrium constants (see Fig. 9).

A slower advance of the reaction front is observed for those combinations that correspond to higher concentrations of A-therefore closer to the bulk ones-at the reaction front. Note that, for the same stoichiometric coefficients, the rate of advance of the reaction front, and therefore the value of $\tau$, depends on the value of $K_{\mathrm{E}}$ alone. However, for varying stoichiometric coefficients and equilibrium constants, the progress of the reaction front is determined by the concentrations at the reaction front, which depend on both $\eta$ and $K_{\mathrm{E}}$ and can only be known by solution of the boundary conditions.
A comparison has been made between the results obtained with $r$ for several numbers of collocation points (see Fig. 10).

As can be seen the solution converges to the correct one as the number of collocation points increases. The main deviation occurs as the length of zone 1 tends to zero, but even relatively low numbers of collocation points (e.g. 6) in both zones yield an acceptable solution in which the curve retains the correct shape.

\subsection{Comparison with previous models}

A very important issue is whether the model proposed in this study is different from well-known previous models (see Levenspiel (1972, 1993)). In reality, as has been already shown, there are significant differences between this model and the mass transfer-limited models presented by Levenspiel, namely because they are based on different assumptions and because they produce different results.

Previous models are based, as has already been mentioned, on the pseudo-steady state assumption, valid if the accumulation term $\frac{\partial C}{\partial t}$ is negligible. Since the model and resolution proposed in this work are not based on this assumption, they can therefore be used for concentrated solutions (although, in the case of electrolytes, the effective diffusion coefficients may have to be estimated by more sophisticated methods). The validity

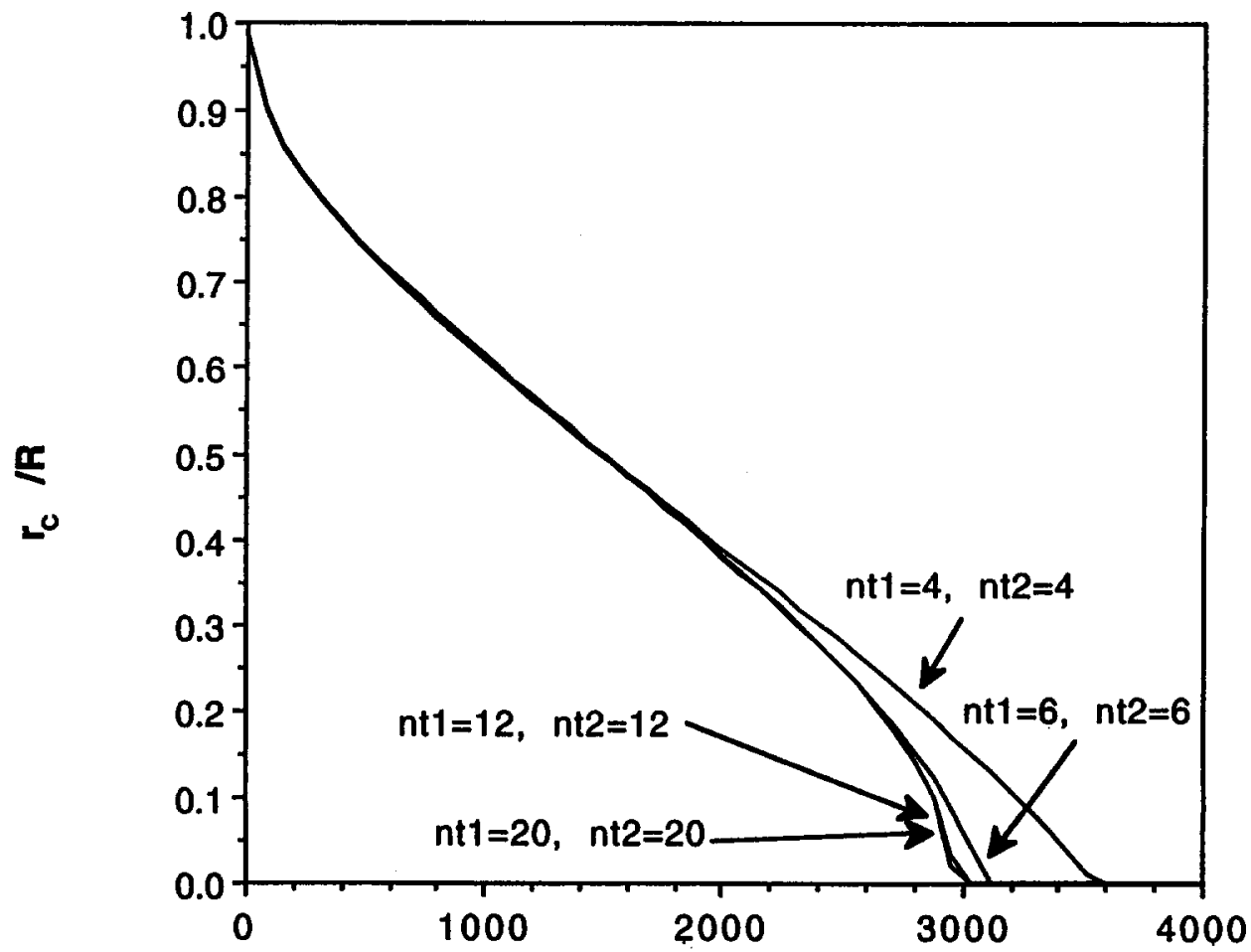

t (s)

Fig. 10. Influence of the number of discretization points on the solution obtained using $r$ as the spatial independent variable. 
of this assumption depends on the parameters used and will not be discussed further; however, our model is valid for a broader range of concentrations.

Also, previous models are based on the assumption of irreversible reaction. As previously shown, the variation of $r_{c} / R$ with $t / \tau$ (where $\tau$ is the time it takes for the particle to react completely) is similar. However, this only means that the shape of the curve is similar, not the curve itself since the $X$ axes have different scaling factors $(1 / \tau)$. The reversibility of the reaction leads to a decrease in the driving force for diffusion, since the concentration of $\mathrm{A}$ is higher, at the reaction front, than zero. This means that the values of $\tau$, besides being different from the ones predicted by Levenspiel, are also dependent on the equilibrium constant and stoichiometric coefficients. Longer times are obtained for lower values of $K_{\mathrm{E}}$, i.e. greater degrees of reversibility. In general, reversibility leads to retardation of the advance of the reaction front, as compared to the irreversible case. This being so, the models presented by Levenspiel for mass transfer-limited gas-solid reactions are a simplified, particular case of the model proposed in this study, where

a) the term $\frac{\partial C}{\partial t}$ has been neglected;

b) $K_{\mathrm{E}}$ is assumed to tend to $+\infty$, i.e. the reaction can be assumed to be irreversible. This leads to the further assumption that the concentration of $A$ at the reaction interface is nil.

They cannot predict, in the case of reversible reactions,

a) the internal concentration profiles of $\mathrm{A}$ and $\mathrm{B}$, including the concentrations at the reaction interface (which, in the case of a reversible reaction, depend on the profiles themselves, on the equilibrium constant, and on the stoichiometric coefficients, and cannot be known a priori);

b) the time it takes for the particle to react completely $(\tau)$;

c)since they do not include the additional parameter $K_{\mathrm{E}}$, or the stoichiometric coefficients $\eta$, they cannot predict the influence of the degree of the reversibility on the behaviour of the particle.

\section{Conclusions}

It has been shown that, under certain circumstances, a sharp reaction interface model can be valid in the case of a non-catalytic liquid-solid reversible reaction. Being purely diffusional in both the unreacted core and the ash layer, this model is obviously influenced by mass transfer and physical parameters. The effect of reversibility is similar to a decrease in the driving force for diffusion-or to a decrease in the effective diffusion coefficients, for that matter-due to an increase in the concentration of $\mathrm{A}$ at the reaction front compared to the irreversible case.

\section{References}

Angevine, P. (1983) Cost-effective causticizing. In 1983 Engineering Conference/TAPPI Proceedings, Book 1, Ch. 42, pp. 253-265, Dallas, Texas, USA. Technical Association of the Pulp and Paper Industry.

Blackwell, B. (1987) Increasing white liquor causticity by addressing the diffusion limitation. Pulp and Paper Canada 88, 87-94.

Blasiński, H. and Amanowitz, M. (1979) Diffusion in a porous solid: methods for determining the effective diffusion coefficient. International Chemical Engineering 19, 236-239.

Doraiswamy, L. K. and Sharma, M. M. (1984) Heterogeneous Reactions: Analysis, Examples and Reaction Design. Volume 1: Gas-solid and solid-solid reactions. Wiley, New York.

Dorris, G. M. and Allen, L. H. (1985) The effect of reburned lime structure on the rates of slaking, causticizing and lime mud settling. Journal of Pulp and Paper Science 11, J89-J98.

Dorris, G. M. and Allen, L. H. (1986) Physicochemical aspects of recausticizing. In D. W. Reeve (Ed.), Kraft Recovery Operations Seminar/TAPPI Seminar Notes, Ch. 23, pp. 7-19, Orlando, Florida, USA. Technical Association of the Pulp and Paper Industry.

Dorris, G. M. (1990) Equilibrium of the causticizing reaction and its effect on slaker control strategies. In Pulping Conference/TAPPI Proceedings, Ch. 58, pp. 245-251, Toronto, Ontario, Canada.

Georgakis, C., Chang, C. W. and Szekely, J. (1979) A changing grain size model for gas-solid reactions. Chemical Engineering Science 34, 1072-1075.

Hindmarsh, A. C. (1980) LSODE and LSODI: two new initial value ordinary differential equation solvers. ACM Signum Newsletters 15, 10-11.

Ishida, M. and Wen, C. Y. (1968) Comparison of kinetic and diffusional models for gas-solid reactions. AIChE Journal 14, 311-317.

Leaist, D. G. and Noulty, R. A. (1985) Multicomponent diffusion of aqueous sodium carbonate and aqueous sodium bicarbonate. Canadian Journal of Chemistry 63, 2313-2319.

Levenspiel, O. (1972) Chemical Reaction Engineering, 2nd ed. Wiley, New York.

Levenspiel, O. (1993) The Chemical Reactor Omnibook. OSU Book Stores, Inc., Corvallis, OR.

Lindberg, H. and Ulmgren, P. (1983) Equilibrium studies of white liquor preparation in kraft mills. Journal of Pulp and Paper Science 9, TR7-TR12.

Noulty, R. A. and Leaist, D. G. (1984) Activity coefficients and diffusion coefficients of dilute aqueous solutions of lithium, sodium and potassium hydroxides. Journal of Solution Chemistry 13, 767-778.

Pais, F. I. C. C. and Portugal, A. A. T. G. Determination of the Steady-State of Isothermal Two-Phase Continuous Stired Tank Reactors. Chem. Eng. Sci. 49, 3447-3456 (1994).

Pais, F. I. C. C. and Portugal, A. A. T. G. Steady-State Behaviour of Isothermal Two-Phase Continuous Sirred Tank Reactors for Extreme Solids Concentrations. Chem. ENg. Sci. 51, 321-323 (1996).

Park, J. Y. and Levenspiel, O. (1975) The crackling core 
model for the reaction of solid particles. Chemical Engineering Science 30, 1207-1214.

Park, J. Y. and Levenspiel, O. (1977) The crackling core model for the multistep reaction of solid particles. Chemical Engineering Science 32, 233-234.

Portugal, A. A. T. G. and Pais, F. I. C. C. (1989) A mathematical model for the causticizing reaction. In L. Sousa Loba and J. Vital (Eds.), Proceedings of Chempor '89, International Chemical Engineering Conference, Lisbon, Portugal, pp. 8R1-8R8.

Ramachandran, P. A. and Doraiswamy, L. K. (1982) Modeling of non-catalytic gas-solid reactions. AIChE Journal 28, 881-900.

Ranade, P. V. and Harrison, D. P. (1979) The grain model applied to porous solids with varying structural properties. Chemical Engineering Science 34, 427-432.

Rydin, S. (1978) The kinetics of the causticizing reaction. Svensk Papperstidning 2, 43-48.

Sohn, H. Y. and Szekely, J. (1972) A structural model for gas-solid reactions with a moving boundary-III: A general dimensionless representation of the irreversible reaction between a porous solid and a reactant gas. Chemical Engineering Science 27, 763-778.

Stamatakis, K. and Tien, C. (1991) Cake formation and growth in cake filtration. Chemical Engineering Science 46, 1917-1933.

Szekely, J. and Evans, J. W. (1970) A structural model for gas-solid reactions with a moving boundary. Chemical Engineering Science 25, 1091-1107.

Szekely, J. and Evans, J. W. (1971) A structural model for gas-solid reactions with a moving boundaryII: The effect of grain size, porosity and temperature on the reaction of porous pellets. Chemical Engineering Science 26, 1901-1913.

Villadsen, J. and Michelsen, M. L. (1976) Solution of Differential Equations Models by Polynomial Approximation. Prentice-Hall Inc., Englewood Cliffs, NJ.

Weast, R. C. (1983) CRC Handbook of Chemistry and Physics, ed. R. C. Weast, 64th ed. CRC Press, Boca Raton, FL.

Yagi, S. and Kunii, D. (1955) 5th Symposium (International) on Combustion, p. 231. Reinhold, New York.

\section{Appendix A}

\section{Discretization using orthogonal collocation}

If the number of collocation points in the inner zone is $n_{\mathrm{t} 1}$ and the number of collocation points in the outer zone is $n_{\mathrm{t} 2}$, then variables 1 to $n_{11}$ correspond to concentration of $A$ in the inner zone, from $n_{11}+1$ to $2 n_{t 1}$ to concentration of $B$ in the inner zone, from $2 n_{11}+1$ to $2 n_{11}+n_{12}$ to concentration of $\mathrm{A}$ in the outer zone, and from $2 n_{11}+n_{\mathrm{t} 2}+1$ to $2 n_{\mathrm{t} 1}+2 n_{12}$ to concentration of $\mathrm{B}$ in the outer zone. Concentrations in both zones must be equal at the reaction front, i.e. $y\left(n_{11}\right)=y\left(2 n_{11}+1\right)$ and $y\left(2 n_{11}\right)=y\left(2 n_{t 1}+n_{12}+1\right)$.

$$
\frac{\mathrm{d} y(i)}{\mathrm{d} t}-\frac{\eta_{1}(i)}{\eta_{\mathrm{c}}} \frac{\mathrm{d} \eta_{\mathrm{c}}}{\mathrm{d} t} \sum_{k=1}^{n_{4}} v_{1}(1, i, k) y(k)
$$

$$
\begin{aligned}
& =\frac{D_{\mathrm{cAl}}}{\varepsilon_{1} R^{2} \eta_{c}^{2}}\left(\frac{2}{\eta_{1}(i)} \sum_{k=1}^{n_{1}} v_{1}(1, i, k) y(k)+\sum_{k=1}^{n_{4}} v_{2}(1, i, k) y(k)\right) \\
& i=2, n_{11}-1 \\
& \frac{\mathrm{d} y(i)}{\mathrm{d} t}-\frac{\eta_{1}\left(i-n_{11}\right)}{\eta_{\mathrm{c}}} \frac{\mathrm{d} \eta_{\mathrm{c}}}{\mathrm{d} t} \\
& \times \sum_{k=1}^{114} v_{1}\left(1, i-n_{11}, k\right) y\left(n_{\mathrm{t1}}+k\right) \\
& =\frac{D_{e \mathrm{~B} \mid}}{\varepsilon_{\mathrm{l}} R^{2} \eta_{c}^{2}}\left(\frac{2}{\eta_{1}\left(i-n_{\mathrm{i}}\right)}\right. \\
& \times \sum_{k=1}^{n_{41}} v_{1}\left(1, i-n_{\mathrm{t1}}, k\right) y\left(n_{\mathrm{t} 1}+k\right) \\
& \left.+\sum_{k=1}^{n_{4}} v_{2}\left(1, i-n_{\mathrm{tl}}, k\right) y\left(n_{\mathrm{t1}}+k\right)\right) \\
& i=n_{11}+2,2 n_{11}-1 \\
& \frac{\mathrm{d} y(i)}{\mathrm{d} t}-\frac{1-\eta_{2}\left(i-2 n_{\mathrm{t} 1}\right)\left(1-\eta_{\mathrm{c}}\right)+\eta_{\mathrm{c}}}{\left(1-\eta_{\mathrm{c}}\right)^{2}} \\
& \times \sum_{k=1}^{n_{\mathrm{z}}} v_{1}\left(2, i-2 n_{\mathrm{t}}, k\right) y\left(2 n_{\mathrm{t1}}+k\right) \frac{\mathrm{d} \eta_{\mathrm{c}}}{\mathrm{d} t} \\
& =\frac{D_{\mathrm{eA} 2}}{\varepsilon_{2} R^{2}\left(1-\eta_{\mathrm{c}}\right)}\left(\frac{2}{\eta_{2}\left(i-2 n_{\mathrm{t}}\right)\left(1-\eta_{\mathrm{c}}\right)+\eta_{\mathrm{c}}}\right. \\
& \times \sum_{k=1}^{n_{12}} v_{1}\left(2, i-2 n_{\mathrm{t1}}, k\right) y\left(2 n_{\mathrm{t1}}+k\right) \\
& \left.+\frac{1}{1-\eta_{\mathrm{c}}} \sum_{k=1}^{n_{12}} v_{2}\left(2, i-2 n_{\mathrm{t1}}, k\right) y\left(2 n_{\mathrm{t1}}+k\right)\right) \\
& i=2 n_{\mathrm{t} 1}+2,2 n_{\mathrm{t} 1}+n_{\mathrm{t} 2}-1 \\
& \frac{\mathrm{d} y(i)}{\mathrm{d} t}-\frac{1-\eta_{2}\left(i-2 n_{11}-n_{12}\right)\left(1-\eta_{\mathrm{c}}\right)+\eta_{\mathrm{c}}}{\left(1-\eta_{\mathrm{c}}\right)^{2}} \\
& \times \sum_{k=1}^{n_{12}} v_{1}\left(2, i-2 n_{11}-n_{12}, k\right) y\left(2 n_{11}+n_{\mathrm{t} 2}+k\right) \frac{\mathrm{d} \eta_{c}}{\mathrm{~d} t}
\end{aligned}
$$

$$
\begin{aligned}
& =\frac{D_{\mathrm{eB} 2}}{\varepsilon_{2} R^{2}\left(1-\eta_{\mathrm{c}}\right)}\left(\frac{2}{\eta_{2}\left(i-2 n_{\mathrm{t} 1}-n_{\mathrm{l} 2}\right)\left(1-\eta_{\mathrm{c}}\right)+\eta_{\mathrm{c}}} \times\right. \\
& \times \sum_{k=1}^{n_{12}} v_{1}\left(2, i-2 n_{\mathrm{t} 1}-n_{\mathrm{t},}, k\right) y\left(2 n_{\mathrm{t1}}+n_{\mathrm{t} 2}+k\right)+ \\
& \left.+\frac{1}{1-\eta_{c}} \sum_{k=1}^{n_{12}} \nu_{2}\left(2, i-2 n_{\mathrm{t1}}-n_{\mathrm{t} 2}, k\right) y\left(2 n_{\mathrm{tt}}+n_{\mathrm{t} 2}+k\right)\right) \\
& i=2 n_{\mathrm{t} 1}+n_{\mathrm{t} 2}+2,2 n_{\mathrm{t} 1}+2 n_{\mathrm{t} 2}-1 \\
& \frac{\mathrm{d} \eta_{\mathrm{c}}}{\mathrm{d} t}=-\frac{C_{\mathrm{A}}^{0}}{R^{2} C_{\mathrm{R}}^{\mathrm{in}}} \frac{\eta_{\mathrm{R}}}{\eta_{\mathrm{A}}} \times
\end{aligned}
$$




$$
\begin{aligned}
& \times\left(\frac{D_{\text {eA } 2}}{a-\eta_{c}} \sum_{k=1}^{n_{12}} v_{1}(2,1, k) y\left(2 n_{\mathrm{t}}+k\right)\right. \\
& \left.-\frac{D_{\mathrm{eA} 1}}{\eta_{\mathrm{c}}} \sum_{k=1}^{n_{14}} \nu_{1}\left(1, n_{\mathrm{t} 1}, k\right) y(k)\right)
\end{aligned}
$$

$\sum_{k=1}^{m} v_{1}(1,1, k) y(k)=0$

$\sum_{k=1}^{n_{4}} v_{1}(1,1, k) y\left(n_{11}+k\right)=0$

$K_{\mathrm{LA}}\left(1-y\left(2 n_{\mathrm{t1}}+n_{12}\right)\right)=\frac{D_{\mathrm{eA} 2}}{R\left(1-\eta_{\mathrm{c}}\right)} \sum_{k=1}^{n_{12}} v_{1}\left(2, n_{12}, k\right) y\left(2 n_{\mathrm{t}}+k\right)$

$K_{\mathrm{LB}}\left(1-y\left(2 n_{\mathrm{t} 1}+2 n_{12}\right)\right)=\frac{D_{\mathrm{eB} 2}}{R\left(1-\eta_{\mathrm{c}}\right)} \sum_{k=1}^{n_{12}} v_{1}\left(2, n_{12}, k\right) y\left(2 n_{\mathrm{t} 1}+n_{\mathrm{L}}+k\right)$

$\frac{D_{\mathrm{eA} 2}}{1-\eta_{\mathrm{c}}} \sum_{k=1}^{n_{\mathrm{i}}} v_{1}(2,1, k) y\left(2 n_{\mathrm{t} 1}+k\right)-\frac{D_{\mathrm{eA}}}{\eta_{\mathrm{c}}} \sum_{k=1}^{n_{\mathrm{H}}} v_{1}\left(1, n_{\mathrm{tl}}, k\right) y(k)$

$$
=-\frac{\eta_{\mathrm{A}}}{\eta_{\mathrm{B}}} \frac{C_{\mathrm{B}}^{0}}{C_{\mathrm{A}}^{0}}\left[\frac{D_{\mathrm{eB} 2}}{1-\eta_{\mathrm{c}}} \sum_{k=1}^{n_{\mathrm{k}}} v_{\mathrm{i}}(2,1, k) y\left(2 n_{\mathrm{t}}+n_{12}+k\right)\right.
$$

$$
\left.-\frac{D_{\mathrm{eB} 1}}{\eta_{\mathrm{c}}} \sum_{k=1}^{n_{41}} v_{1}\left(1, n_{11}, k\right) y\left(n_{\mathrm{t} 1}+k\right)\right]
$$

$\frac{y\left(2 n_{11}\right)^{\eta_{B}}}{y\left(n_{11}\right)^{\eta_{A}}}=K_{\mathrm{E}} \frac{C_{\mathrm{A}}^{0 \eta_{A}}}{C_{\mathrm{B}}^{0 \eta_{\mathrm{B}}}}$

$y\left(2 n_{11}+1\right)=y\left(n_{t 1}\right)$

$y\left(2 n_{\mathrm{t} 1}+n_{\mathrm{t} 2}+1\right)=y\left(2 n_{\mathrm{t} 1}\right)$

\section{Appendix B}

\section{Solution of the boundary conditions}

The discretized boundary conditions $((29)-(36))$ correspond to a system of eight equations in eight unknowns. If (35) and (36) are used to eliminate two variables, we obtain:

$$
\begin{aligned}
& a y(1)+b y\left(n_{11}\right)+c_{1}=0 \\
& a y\left(n_{\mathrm{t} 1}+1\right)+b y\left(2 n_{11}\right)+c_{2}=0 \\
& e_{1} y\left(2 n_{11}+n_{12}\right)+f y\left(n_{11}\right)-d_{1}=0 \\
& e_{2} y\left(2 n_{11}+2 n_{12}\right)+f y\left(2 n_{11}\right)-d_{2}=0 \\
& g_{1} y\left(n_{11}\right)+h_{1} y\left(2 n_{11}+n_{12}\right)+o_{1} y(1)= \\
& =g_{2} y\left(2 n_{11}\right)+h_{2} y\left(2 n_{11}+2 n_{12}\right)+o_{2} y\left(n_{11}+1\right)+p \\
& \left(y\left(2 n_{11}\right)\right)^{n_{11}}=q\left(y\left(n_{11}\right)\right)^{n_{1}}
\end{aligned}
$$

$$
a=v_{1}(1,1,1)
$$$$
b=v_{1}\left(1,1, n_{11}\right)
$$$$
c_{1}=\sum_{k=2}^{n_{1}-1} v_{1}(1,1, k) y(k)
$$$$
c_{2}=\sum_{k=2}^{n} \sum_{1}^{-1} v_{1}(1,1, k) y\left(n_{11}+k\right)
$$

$$
d_{1}=\frac{K_{\mathrm{LA}} R}{D_{\mathrm{eA} 2}}\left(1-\eta_{\mathrm{c}}\right)-\sum_{k=2}^{n_{2}-1} v_{1}\left(2, n_{\mathrm{t} 2}, k\right) y\left(2 n_{\mathrm{t} 1}+k\right)
$$$$
d_{2}=\frac{K_{\mathrm{LB}} R}{D_{\mathrm{eB} 2}}\left(1-\eta_{\mathrm{c}}\right)-\sum_{k=2}^{n_{\mathrm{c}}-1} v_{1}\left(2, n_{\mathrm{t} 2}, k\right) y\left(2 n_{\mathrm{t} 1}+n_{\mathrm{t} 2}+k\right)
$$$$
e_{1}=v_{1}\left(2, n_{\mathrm{Q}}, n_{\mathrm{t} 2}\right)+\frac{K_{\mathrm{LA}} R}{D_{\mathrm{eA} 2}}\left(1-\eta_{\mathrm{c}}\right)
$$$$
e_{2}=v_{1}\left(2, n_{12}, n_{12}\right)+\frac{K_{\mathrm{LB}} R}{D_{\mathrm{eB2} 2}}\left(1-\eta_{\mathrm{c}}\right)
$$

$f=v_{1}\left(2, n_{\mathrm{t} 2}, 1\right)$

$g_{1}=\frac{D_{\mathrm{eA} 2}}{1-\eta_{\mathrm{c}}} v_{1}(2,1,1)-\frac{D_{\mathrm{eA} 1}}{\eta_{\mathrm{c}}} v_{1}\left(1, n_{\mathrm{t} 1}, n_{\mathrm{t} 1}\right)$

$g_{2}=-\frac{\eta_{\mathrm{A}}}{\eta_{\mathrm{B}}} \frac{C_{\mathrm{B}}^{0}}{C_{\mathrm{A}}^{0}} \frac{D_{\mathrm{eB} 2}}{1-\eta_{\mathrm{c}}} v_{1}(2,1,1)+\frac{\eta_{\mathrm{A}}}{\eta_{\mathrm{B}}} \frac{C_{\mathrm{B}}^{0}}{C_{\mathrm{A}}^{0}} \frac{D_{\mathrm{eB} 1}}{\eta_{\mathrm{c}}} v_{1}\left(1, n_{\mathrm{t} 1}, n_{\mathrm{t} 1}\right)$

$h_{1}=\frac{D_{\mathrm{eA} 2}}{1-\eta_{\mathrm{c}}} v_{1}\left(2,1, n_{\mathrm{t} 2}\right)$

$h_{2}=-\frac{\eta_{\mathrm{A}}}{\eta_{\mathrm{B}}} \frac{C_{\mathrm{B}}^{0}}{C_{\mathrm{A}}^{0}} \frac{D_{\mathrm{eB} 2}}{1-\eta_{\mathrm{c}}} v_{1}\left(2,1, n_{\mathrm{B}}\right)$

$o_{1}=-\frac{D_{\text {eAl }}}{\eta_{\mathrm{c}}} v_{1}\left(1, n_{\mathrm{t}}, 1\right)$

$o_{2}=\frac{\eta_{\mathrm{A}}}{\eta_{\mathrm{B}}} \frac{C_{\mathrm{B}}^{0}}{C_{\mathrm{A}}^{0}} \frac{D_{\mathrm{eB} 1}}{\eta_{\mathrm{c}}} \nu_{1}\left(1, n_{\mathrm{t} 1}, 1\right)$

$p=-\frac{\eta_{\mathrm{A}}}{\eta_{\mathrm{B}}} \frac{C_{\mathrm{B}}^{0}}{C_{\mathrm{A}}^{0}} \frac{D_{\mathrm{eB} 2}}{1-\eta_{\mathrm{c}}} \sum_{k=2}^{n_{2}-1} v_{1}(2,1, k) y\left(2 n_{\mathrm{t} 1}+n_{\mathrm{t} 2}+k\right)+$

$+\frac{\eta_{\mathrm{A}}}{\eta_{\mathrm{B}}} \frac{C_{\mathrm{B}}^{0}}{C_{\mathrm{A}}^{0}} \frac{D_{\mathrm{eB} \mid}}{\eta_{\mathrm{c}}} \sum_{k=2}^{n_{1}-1} v_{1}\left(1, n_{\mathrm{t} \mid}, k\right) y\left(n_{11}+k\right)-$

$-\frac{D_{\mathrm{eA} 2}}{1-\eta_{\mathrm{c}}} \sum_{k=2}^{n_{12}-1} v_{1}(2,1, k) y\left(2 n_{\mathrm{t} 1}+k\right)+\frac{D_{\mathrm{eA} 1}}{\eta_{\mathrm{c}}} \sum_{k=2}^{n_{1}-1} v_{1}\left(1, n_{11}, k\right) y(k)$

$q=K_{\mathrm{E}} \frac{C_{\mathrm{A}}^{0^{m \mu}}}{C_{\mathrm{B}}^{0^{\text {\# }}}}$

After appropriate substitution and elimination of variables we obtain

$y\left(2 n_{11}\right)^{n_{3}}=q\left(\frac{s+r_{2} y\left(2 n_{11}\right)}{r_{1}}\right)^{\eta_{n}}$

where

$r_{1}=g_{1}-\frac{f h_{1}}{e_{1}}-\frac{b o_{1}}{a}$

$r_{2}=g_{2}-\frac{f h_{2}}{e_{2}}-\frac{b o_{2}}{a}$ 
$s=\frac{d_{2} h_{2}}{e_{2}}-\frac{c_{2} o_{2}}{a}-\frac{d_{1} h_{1}}{e_{1}}+\frac{c_{1} o_{1}}{a}+p$.

If $\eta_{\mathrm{A}}=1$ and $\eta_{\mathrm{B}}=1$, that is, if the system of equations is linear, then resolution will be straightforward. If (38) is or can be transformed into second or third order, then resolution by means of a solvent formula is possible (as in the case of the causticizing reaction, where $\eta_{\mathrm{A}}=1$ and $\eta_{\mathrm{B}}=2$ ). In all other cases a numerical iterative method must be used, such as the bisection method. More effective methods such as Newton-Raphson may be impossible to use as the coefficients of (38) are highly timedependent and guarantee of convergence is not possible. Care must be taken, where more than one solution exists, to choose the physically meaningful solution.If $\eta_{c}<\eta_{\text {clim }}$, then diffusion alone will take place. (33) and (34) will no longer hold, which means that concentrations of $A$ and $B$ are uncoupled at the reaction front, and will be replaced by

$$
\begin{aligned}
& \frac{D_{\mathrm{eA} 2}}{1-\eta_{\mathrm{c}}} \sum_{k=1}^{n_{n}} \nu_{1}(2,1, k) y\left(2 n_{\mathrm{t1}}+k\right)=\frac{D_{\mathrm{eA} 1}}{\eta_{\mathrm{c}}} \sum_{k=1}^{n_{\mathrm{A} 1}} v_{\mathrm{i}}\left(1, n_{\mathrm{t} 1}, k\right) y(k) \\
& \frac{D_{\mathrm{eB} 2}}{1-\eta_{\mathrm{c}}} \sum_{k=1}^{n_{1 \mathrm{~B}}} v_{\mathrm{l}}(2,1, k) y\left(2 n_{11}+n_{\mathrm{1}}+k\right)=\frac{D_{\mathrm{eB} 1}}{\eta_{\mathrm{c}}} \sum_{k=1}^{n_{41}} v_{1}\left(1, n_{\mathrm{t}}, k\right) y\left(n_{11}+k\right)
\end{aligned}
$$

Together with (29) to (32), (35) and (36), another system must be solved in order to determine concentrations at the boundaries:

$$
\begin{aligned}
& a_{1} y(1)+b_{1} y\left(n_{\mathrm{t}}\right)+c_{1} y\left(2 n_{\mathrm{t} 1}+n_{12}\right)=d_{1} \\
& e y(1)+f y\left(n_{\mathrm{t1}}\right)+g_{1}=0 \\
& h y\left(n_{11}\right)+o_{1} y\left(2 n_{\mathrm{t} 1}+n_{12}\right)+p_{1}=0 \\
& a_{2} y\left(n_{11}+1\right)+b_{2} y\left(2 n_{11}\right)+c_{2} y\left(2 n_{11}+2 n_{12}\right)=d_{2} \\
& \operatorname{ey}\left(n_{11}+1\right)+f y\left(2 n_{11}\right)+g_{2}=0 \\
& h y\left(2 n_{11}\right)+o_{2} y\left(2 n_{\mathrm{t} 1}+2 n_{12}\right)+p_{2}=0
\end{aligned}
$$

where

$$
\begin{aligned}
& a_{1}=-\frac{D_{\text {eAl }}}{\eta_{\mathrm{c}}} v_{\mathrm{l}}\left(1, n_{\mathrm{t}}, 1\right) \\
& a_{2}=-\frac{D_{e \mathrm{~B} 1}}{\eta_{\mathrm{c}}} v_{1}\left(1, n_{\mathrm{t} 1}, 1\right) \\
& b_{1}=\frac{D_{\mathrm{eA} 2}}{1-\eta_{\mathrm{c}}} v_{1}(2,1,1) \\
& b_{2}=\frac{D_{\mathrm{eB} 2}}{1-\eta_{\mathrm{c}}} v_{1}(2,1,1) \\
& c_{1}=\frac{D_{\mathrm{eA} 2}}{1-\eta_{\mathrm{c}}} \nu_{1}\left(2,1, n_{\mathrm{L}}\right) \\
& c_{2}=\frac{D_{\mathrm{eB} 2}}{1-\eta_{\mathrm{c}}} v_{1}\left(2,1, n_{12}\right) \\
& d_{1}=\frac{D_{\mathrm{eA} 1}}{\eta_{\mathrm{c}}} \sum_{k=2}^{n_{1}-1} v_{1}\left(1, n_{\mathrm{t} 1}, k\right) y(k)-\frac{D_{\mathrm{eA} 2}}{1-\eta_{\mathrm{c}}} \\
& X \sum_{k=2}^{n_{12}-1} v_{1}(2,1, k) y\left(2 n_{11}+k\right) \\
& d_{2}=\frac{D_{\mathrm{eB} 1}}{\eta_{\mathrm{c}}} \prod_{k=2}^{n !-1} v_{1}\left(1, n_{\mathrm{t} 1}, k\right) y\left(n_{\mathrm{t} 1}+k\right)-\frac{D_{\mathrm{eB} 2}}{1-\eta_{\mathrm{c}}} \\
& \times \sum_{k=2}^{n_{12}-1} v_{1}(2,1, k) y\left(2 n_{11}+n_{12}+k\right) \\
& e=v_{1}(1,1,1) \\
& f=v_{1}\left(1,1, n_{\mathrm{t} 1}\right) \\
& g_{1}=\sum_{k=2}^{n} \sum_{1}^{-1} v_{1}(1,1, k) y(k) \\
& g_{2}=\sum_{k=2}^{n-1} v_{1}(1,1, k) y\left(n_{11}+k\right) \\
& h=v_{1}\left(2, n_{\mathrm{t} 2}, 1\right) \\
& o_{1}=v_{1}\left(2, n_{\mathrm{t} 2}, n_{12}\right)+\frac{K_{\mathrm{LA}} R}{D_{\mathrm{eA} 2}}\left(1-\eta_{\mathrm{c}}\right) \\
& o_{2}=v_{1}\left(2, n_{\mathrm{L} 2}, n_{12}\right)+\frac{K_{\mathrm{LB}} R}{D_{\mathrm{eB} 2}}\left(1-\eta_{\mathrm{c}}\right) \\
& p_{1}=\sum_{k=2}^{n{ }^{2}-1} v_{1}\left(2, n_{\mathrm{t} 2}, k\right) y\left(2 n_{11}+k\right)-\frac{K_{\mathrm{LA}} R}{D_{\mathrm{eA} 2}}\left(1-\eta_{\mathrm{c}}\right) \\
& p_{2}=\sum_{k=2}^{11} v_{1}\left(2, n_{\mathrm{t} 2}, k\right) y\left(2 n t 1+n_{12}+k\right)-\frac{K_{\mathrm{LB}} R}{D_{\mathrm{eB} 2}}\left(1-\eta_{\mathrm{c}}\right)
\end{aligned}
$$

